\title{
EL DESPERDICIO DE ALIMENTOS COMO EXTERNALIDAD NEGATIVA: SOLUCIONES CONTENIDAS EN LA NORMATIVA FRANCESA Y PROPUESTAS PARA EL CASO ESPAÑOL
}

\section{FOOD WASTE AS A NEGATIVE EXTERNALITY: THE FRENCH LEGAL RESPONSE AND PROPOSALS FOR THE SPANISH LEGAL FRAMEWORK}

\author{
M. Teresa Armengol Rosinés \\ Profesora titular de Universidad \\ Departamento de Economía Aplicada, Universidad de Lleida \\ Teresa.Armengol@econap.udl.cat \\ LAURA SALAMERO TEIXIDÓ \\ Profesora lectora (acreditada a agregada) de Derecho administrativo \\ Departamento de Derecho Público, Universidad de Lleida \\ Isalamero@dpub.udl.cat \\ MANel Plana FARRAN \\ Profesor asociado \\ Departamento de Administración de Empresas, Universidad de Lleida \\ mplana@aegern.udl.cat
}

Fecha de recepción: 26 de julio de 2019 / Fecha de aceptación: 26 de octubre de 2019

RESUMEN: Según la FAO, un tercio de todos los alimentos producidos en el mundo acaban tirándose. Las consecuencias de tal derroche no son solo económicas, sociales y éticas, sino también medioambientales. El desperdicio por parte de los consumidores y distribuidores genera importantes costes medioambientales sin que ninguna de las partes involucradas en las actividades de distribución y consumo asuma dichos costes sociales. En el marco de la teoría económica de las externalidades, el trabajo detalla las soluciones que la legislación francesa incorporó en 2016 de lucha contra el desperdicio de alimentos con una norma pionera en el contexto europeo. Además, se hacen propuestas susceptibles de incorporarse a la legislación que se apruebe en 
España a nivel estatal, autonómico, y también en las ordenanzas fiscales de los municipios.

RESUM: Segons la FAO, un terç de tots els aliments produïts al món es llença. Les conseqüències d'aquest malbaratament no només són econòmiques, socials i ètiques, sinó també mediambientals. El malbaratament per part dels consumidors i dels distribuïdors genera importants costs mediambientals sense que cap de les parts involucrades en les activitats de distribució i consum assumeixi aquests costs socials. En el marc de la teoria econòmica de les externalitats, el treball detalla les solucions que la legislació francesa va incorporar el 2016 en la lluita contra el malbaratament d'aliments amb una norma pionera en el context europeu. A més, es fan propostes susceptibles d'incorporar-se a la legislació que s'aprovi a Espanya a nivell estatal, autonòmic i també en les ordenances fiscals dels municipis.

ABSTRACT: According to the FAO, one-third of all the food that is produced in the world is wasted. The consequences of food waste are not only economic, social and ethical, but also environmental. Waste by consumers and distributors generates significant environmental costs without any of the parties involved in distribution and consumption activities assuming these social costs. Within the framework of the economic theory of externalities, the paper details the solutions to combat food waste foreseen by the pioneering French legislation. After the analysis, we make some proposals to fight against food waste that could be introduced in the Spanish legal framework at the national, regional and local levels.

PALABRAS CLAVE: Desperdicio de alimentos - Externalidad negativa Costes sociales - Costes medioambientales - Regulación directa Instrumentos regulatorios de incentivo económico

PARAULES CLAU: Malbaratament d'aliments - Externalitat negativa - Costs socials - Costs mediambientals - Regulació directa - Instruments reguladors d'incentiu econòmic

KEY WORDS: Food waste - Negative externality - Social costs Environmental costs - Direct regulation - Economic incentives 
SUMARIO: I. Presentación. II. Acotación conceptual III. Causas del desperdicio de alimentos. 1. El desperdicio de alimentos en los hogares. 2. El desperdicio de alimentos en la distribución. IV. El desperdicio de alimentos como externalidad económica negativa: los costes sociales medioambientales del desperdicio alimentario. 1. Justificación del desperdicio alimentario como externalidad negativa. 2. Soluciones al problema de las externalidades: regulación directa e instrumentos de incentivo económico. V. La normativa francesa de lucha contra el desperdicio de alimentos: descripción y análisis de la norma desde la perspectiva de la teoría de las externalidades. 1. Imposición de una jerarquía de acciones. 2. Prohibición de tirar alimentos. 3.la obligación de donar alimentos. 4. Responsabilidad social de las empresas. 5. Las medidas del gobierno francés en el contexto de la teoría de las externalidades. VI Propuestas al problema del impacto ambiental del desperdicio alimentario. 1. Actual marco normativo sobre el desperdicio alimentario en España. 2. Propuestas en atención al modelo francés. 3. El pago por generación: otra propuesta basada en los instrumentos de incentivo económico. a) Concepto de pago por generación. b) Aplicación al caso del desperdicio alimentario. VII. Conclusiones. VI. Bibliografía

\section{PRESENTACIÓN}

El desperdicio de alimentos es un hecho constatado y de creciente relevancia. En los países de la Unión Europea se estima que 88 millones de toneladas de alimentos se pierden o desperdician anualmente (datos del año 2012), lo que representa una media de 173 kilos por persona al año. Los hogares son los que más desperdician: 46,5 millones de toneladas y 42 kilos por persona de media ${ }^{1}$. Según la misma fuente, el $53 \%$ del desperdicio total sucede en los hogares, mientras que el sector de la distribución tira alimentos por valor de 4,6 millones de toneladas ( 9 kilos por persona y año), lo que representa el $5 \%$ del total del desperdicio. No obstante, debe resaltarse que, a pesar de que en la fase del consumo final sea donde se generen más residuos alimentarios, el problema del desperdicio alimentario se produce en todos los eslabones de la cadena alimentaria (sector primario, industria agroalimentaria, distribución y consumo final), y sus causas se hallan en todas ellas.

Las consecuencias derivadas del desperdicio se proyectan en distintas dimensiones. De un lado, la económica, por los recursos económicos destinados en vano a producir alimentos y adquirirlos sin que luego sean destinados al consumo humano. De otro lado, el impacto social y ético, pues mientras que en determinados contextos se tiran alimentos, en otros la inseguridad alimentaria es causa de enfermedades y muerte; fenómeno que acertadamente ha venido a

1 FUSIONS, Estimates of European food waste levels, Estocolmo, 2016. 
denominarse como "paradoja alimentaria contemporánea"2. Y, por último, pero no por ello menos importante, debe tenerse en cuenta el impacto medioambiental asociado al desperdicio de alimentos como, por ejemplo, el consumo de agua y otros recursos naturales invertidos en su producción, o la emisión de gases de efecto invernadero generados por los residuos alimentarios.

De todos los efectos perniciosos del despilfarro, en este trabajo se presta especial atención a los medioambientales, los cuales pueden calificarse claramente como externalidades negativas. Como se explica con más detalle en posteriores epígrafes, el coste medioambiental asociado al desperdicio alimentario no es asumido por ninguna de las partes involucradas en la actividad o transacción económica correspondiente, lo cual hace invisible el problema y, en consecuencia, desincentiva la adopción de medidas para su freno.

A partir de la teoría de las externalidades, el trabajo detalla las soluciones jurídicas propuestas por la normativa francesa de lucha contra el desperdicio de alimentos. El análisis de la norma gala se justifica en el hecho de que Francia ha sido el primer país europeo en legislar mediante una aproximación transversal y multimodal sobre el desperdicio alimentario, de modo que, a fecha de hoy, es la norma europea más omnicomprensiva en esta materia. Asimismo, teniendo en cuenta que en el contexto europeo el desperdicio sucede principalmente en la fase de consumo- entendida como aquella en la que el alimento ha llegado al consumidor: distribución al por menor, sector restauración y hogares-, se analizan con carácter principal las medidas legislativas comprendidas en la norma francesa dirigidas a estos sujetos, en especial, los distribuidores y los hogares.

El objetivo del trabajo es presentar el problema del desperdicio alimentario como una externalidad negativa que genera importantes costes sociales medioambientales y describir las medidas adoptadas por la legislación francesa en la lucha contra el problema del desperdicio. En el trabajo se estudia cómo las soluciones teóricas para hacer frente al problema de las actividades de consumo

\footnotetext{
2 En datos mundiales, más de un tercio de los alimentos acaban desperdiciándose, a la vez que más de 80 millones de personas sufren malnutrición extrema. Utilizan este concepto PLA, L. et al. "La paradoja alimentaria contemporánea en el marco de la justicia ambiental", en Ludus Vitalis, núm. 49, 2018, pp. 133-152.
} 
que generan externalidades negativas se hallan también presentes en el modelo legislativo francés. Además, se realizan propuestas susceptibles de incorporarse a la legislación que eventualmente se apruebe en España, tanto a nivel estatal como autonómico, así como propuestas en el ámbito de las ordenanzas fiscales de los municipios.

El contenido del trabajo se distribuye en siete apartados. Después de esta introducción, en el segundo apartado se presentan algunas de las definiciones del concepto de desperdicio más comúnmente utilizadas, resaltándose su relevancia. A continuación, se discurre brevemente sobre las causas del desperdicio de alimentos en los hogares y en la distribución. En el apartado cuarto, se justifica la consideración del desperdicio alimentario como externalidad económica negativa y se hace referencia al impacto sobre el medio ambiente. El apartado quinto describe la normativa francesa y se analiza la norma desde la perspectiva de la teoría de las externalidades. Finalmente, en el apartado sexto, se articulan diferentes propuestas para paliar el problema del desperdicio de alimentos y, por consiguiente, reducir su impacto ambiental en el contexto del Estado español. Y, por último, el trabajo se cierra con unas breves reflexiones conclusivas.

\section{ACOTACIÓN CONCEPTUAL}

No existe un concepto técnico o legal de "desperdicio alimentario" que sea compartido y aceptado universalmente. La falta de conceptos unívocos en esta arena dificulta sobremanera el estudio de la materia. Por el contrario, conviven distintos conceptos alrededor del desperdicio de alimentos que varían en función del organismo, país, legislación $u$ autor en el que nos fijemos. Dichas divergencias estriban, entre otros, en la distinta perspectiva de aproximación al problema.

Dos son las principales aproximaciones ${ }^{3}$. De un lado, el desperdicio puede abordarse desde la perspectiva de la prevención y gestión de residuos, en cuyo marco los alimentos desperdiciados son otro tipo o categoría de residuo. Esta

3 Pinstrup-Andersen, P. et al., Las pérdidas y el desperdicio de alimentos en el contexto de sistemas alimentarios sostenibles. Un informe del Grupo de alto nivel de expertos en seguridad alimentaria y nutrición del Comité de Seguridad Alimentaria Mundial, FAO, Roma, 2014, pp. 23 y s. 
vertiente es la que se adopta, entre otros, en el marco de la Unión Europea. Otra posible aproximación es la que parte del alimento y según la cual el desperdicio es todo aquel alimento comestible que a lo largo de la cadena se pierde o desperdicia y no llega a cumplir su función primordial de nutrir a los humanos. Esta es la visión que toma, por ejemplo, la FAO. A continuación, se exponen algunos de los conceptos manejados más habitualmente.

La FAO distingue entre el desperdicio y la pérdida de alimentos, según la fase de la cadena alimentaria en la que el alimento deja de destinarse a su fin primario, el consumo humano ${ }^{4}$. Las pérdidas de alimentos "(...) hacen referencia a una disminución de la masa de alimentos destinados originalmente al consumo humano, independientemente de la causa y en todas las fases de la cadena alimentaria antes del ámbito de consumo". En cambio, el desperdicio de alimentos "(...) hace referencia a los alimentos apropiados para el consumo humano que se descartan o se deterioran en el ámbito del consumidor, independientemente de la causa". El ámbito del consumidor incluye la distribución al por menor, el sector de la restauración y los hogares. Ambos conceptos combinados, pérdida y el desperdicio de alimentos (PDA) se define como "(...) una disminución de la masa de alimentos destinados originalmente al consumo humano, independientemente de la causa y en todas las fases de la cadena alimentaria, desde la cosecha hasta el consumo". La FAO toma como punto de partida el alimento comestible, de modo que no considera desperdicio aquellas partes de los alimentos no comestibles como, por ejemplo, la piel de los plátanos, el hueso de las aceitunas o la espina del pescado. Junto a lo anterior, la FAO tiene igualmente en cuenta los factores de seguridad alimentaria (food safety), de modo que el alimento que siendo comestible pierde sus atributos de inocuidad, se convierte en pérdida o desperdicio.

Dentro del marco de la Unión Europea existen distintas definiciones del "desperdicio alimentario" y todas ellas tienen en común un mismo punto de partida: la política medioambiental europea, y la prevención y gestión de residuos como parte fundamental de la misma. Este es el enfoque desde el que las

4 Gustavsson, J. et al., Las pérdidas y el desperdicio de alimentos a nivel mundial. Extensión, causas y prevención, FAO, Roma, 2011. 
instituciones comunitarias abordan el desperdicio alimentario o, mejor dicho, los residuos alimentarios.

Durante años, fue referente en la UE el Proyecto FUSIONS (del inglés, Food Use for Social Innovation by Optimising Waste Prevention Strategies) puesto en marcha por la Comisión Europea entre 2012 y 2016, y dedicado en exclusiva al desperdicio alimentario. En 2014 se publicó un marco conceptual en el que se define el concepto de "desperdicio de alimentos" del siguiente modo: "(...) cualquier alimento, y las partes no comestibles del alimento, que se retiran de la cadena alimentaria para destinarse a fines distintos al consumo humano o para desecharse (lo que incluye el compostaje, cultivos arados/no recolectados, digestión anaeróbica, producción de bioenergía, cogeneración, incineración, eliminación por el sumidero, en un vertedero o en el mar)" [la traducción es nuestra]. Como se ve, en el proyecto FUSIONS no se distingue entre pérdidas y desperdicio, sino que utiliza un único concepto de "desperdicio", que es además más amplio que los conceptos propuestos por la FAO pues incluye las partes no comestibles. Tampoco distingue en atención a la fase de la cadena en la que el alimento deje de destinarse al consumo humano, sino que engloba indistintamente todos los eslabones de la cadena que, a su vez, se define ampliamente desde la fase de producción, incluyendo los productos listos para la cosecha o para el sacrificio, hasta la fase final de consumo.

Junto a la anterior, en la Unión destaca la definición de la Directiva Marco de Residuos. Tras su modificación de $2018^{5}$, se ha incorporado a la Directiva 2008/98/CE del Parlamento Europeo y del Consejo, de 19 de noviembre de 2008, sobre los residuos y por la que se derogan determinadas Directivas (en adelante, Directiva Marco de Residuos o DMR), la primera definición legal del concepto de "desperdicio alimentario" o, desde la vertiente medioambiental, del concepto de "residuo alimentario". El punto de enfoque es el del residuo, y se abandona la terminología de "desperdicio" o "pérdida". Lo que importa ahora del fenómeno del desperdicio alimentario es su gestión e impacto como residuo y, por lo tanto, con carácter principal, su relevancia medioambiental. Según el artículo 3.4.bis de la Directiva define el residuo alimentario como "(...) todos los alimentos, tal de 30 de mayo de 2018, por la que se modifica la Directiva 2008/98/CE sobre los residuos. 
como se definen en el artículo 2 del Reglamento (CE) n. ${ }^{\circ}$ 178/2002 del Parlamento Europeo y del Consejo, que se han convertido en residuos".

La comprensión de la nueva noción exige la incorporación de otros dos conceptos ya definidos en el contexto normativo europeo: a saber, el de "alimento" y el de "residuo". El concepto legal de "alimento" queda recogido en el Reglamento (CE) n 178/2002 del Parlamento Europeo y del Consejo, de 28 de enero de 2002, por el que se establecen los principios y los requisitos generales de la legislación alimentaria, se crea la Autoridad Europea de Seguridad Alimentaria y se fijan procedimientos relativos a la seguridad alimentaria. Según el art. 2 de dicho Reglamento, alimento es "cualquier sustancia o producto destinados a ser ingeridos por los seres humanos o con probabilidad razonable de serlo, tanto si han sido transformados entera o parcialmente como si no". En cuanto al concepto de "residuo", la misma Directiva marco ofrece la siguiente definición en el artículo 4, según el cual se considera residuo "cualquier sustancia u objeto del cual su poseedor se desprenda o tenga la intención o la obligación de desprenderse". Si aplicamos tal definición al ámbito alimentario, residuo alimentario será todo alimento que, con independencia de la causa o del momento de la cadena alimentaria en que se halle, es descartado.

En fin, sin entrar en consideraciones conceptuales en profundidad ${ }^{6}$, en virtud de la Directiva, por primera vez hallamos un concepto legal de "residuo alimentario" que, además, resulta de aplicación a todos los países de la Unión. La trascendencia de lo anterior no es poca. De un lado, porque una vez vayan acotándose los contornos del concepto ello permitirá la unificación de sistemas y metodologías de análisis del fenómeno del desperdicio, así como la comparativa de datos. Del otro, porque la Directiva —que debe trasponerse a

\footnotetext{
$6 \quad$ Véase la Decisión Delegada de la Comisión, de 3 de mayo de 2019, por la que se complementa la Directiva 2008/98/CE del Parlamento Europeo y del Consejo en lo que concierne a una metodología común y a los requisitos mínimos de calidad para la medición uniforme de los residuos alimentarios [C(2019) 3211 final], en la que se aclaran algunos de los flecos del concepto de "residuo alimentario". Así, las partes no comestibles de los alimentos también se consideran residuos, pero se excluyen aquellos productos que aún no se han convertido en alimentos, como las plantas antes de la cosecha o la mayoría de los animales vivos. Téngase en cuenta que, en el momento de elaboración de este trabajo, dicha Decisión no ha entrado todavía en vigor.
} 
más tardar el 5 de julio de 2020 - incluye también determinadas obligaciones para los Estados para la prevención y gestión de los residuos alimentarios ${ }^{7}$.

En el presente trabajo, el concepto de «desperdicio alimentario» que se utiliza converge con la visión europea que se plasma en la definición de FUSIONS. Igualmente, también nos referiremos al concepto de «residuos alimentarios» tal como queda definido en la DMR. Con ello, no obstante, no obviamos la dimensión nutricional de los alimentos, pues en cualquier caso la prevención del desperdicio o de los residuos alimentarios es el principal objetivo de cualquier acción en esta materia.

\section{CAUSAS DEL DESPERDICIO DE ALIMENTOS}

En este epígrafe se analizan con ánimo descriptivo las causas que conducen al desperdicio en estas fases finales de la cadena alimentaria. En tanto que "en Europa y en América del Norte los residuos alimentarios se generan predominantemente en las fases de venta al por menor y consumo"8, estas son las fases en las que prestamos ahora atención. A posteriori y, en consecuencia, nuestras propuestas se dirigirán a estos actores de la cadena alimentaria.

\section{El desperdicio de alimentos en los hogares}

El desperdicio de alimentos que realizan los hogares o consumidores puede explicarse desde el punto de vista de la oferta y de la demanda.

Las causas del desperdicio relacionadas con la oferta tienen que ver con las presiones que las empresas de distribución realizan sobre los hogares con el objetivo de fomentar el gasto en consumo de alimentos y también con el sistema de empaquetado de los productos. En relación con las estrategias de marketing de los distribuidores con el objetivo de dar salida a sus excedentes de alimentos, cabe decir que pueden provocar compras no planificadas, superiores a las necesidades de consumo o incluso compras compulsivas de forma que los

\footnotetext{
7 Vid. art. 9 y Anexo IV bis de la Directiva Marco de Residuos. SALAMERo TEIXIDÓ, L., "Nuevo reto medioambiental en la Unión Europea: la prevención y gestión de los residuos alimentarios según la Directiva Marco de Residuos tras su última modificación", en Revista Española de Derecho Administrativo, núm. 203, 2020.

8 Resolución del Parlamento Europeo, de 19 de enero de 2012, sobre cómo evitar el desperdicio de alimentos: estrategias para mejorar la eficiencia de la cadena alimentaria en la UE (2011/2175(INI).
} 
consumidores acumulan alimentos, algunos de los cuales acabarán por tirar. En el estudio de MONDÉJAR-JIMÉNEZ et al. se pone de manifiesto que las ofertas promocionales animan a los consumidores a comprar más de lo que necesitan y ello promueve el desperdicio alimentario ${ }^{9}$.

Por su parte, el sistema de empaquetado de los productos ha sido señalado también como causa del desperdicio alimentario. En muchos casos, las porciones de los alimentos no se ajustan a las necesidades del hogar. De esta forma, los embalajes grandes provocan que el consumidor adquiera más cantidades de las que necesita y no consuma toda la comida que ha comprado. STUART pone de manifiesto que los supermercados se niegan a mantener envases pequeños, más adecuados para el caso de los hogares unipersonales ${ }^{10}$. MONTAGUT y GASCÓN también señalan que el empaquetado de los alimentos en muchos casos no se adapta a los hábitos de consumo familiar lo que provoca que el consumidor adquiera más alimentos de los que necesita y acabe desperdiciando ${ }^{11}$. Diversos estudios estiman que entre el 20 y el $25 \%$ del desperdicio de los hogares se puede relacionar con los tamaños de los embalajes demasiado grandes ${ }^{12}$.

En este punto es debido destacar que, si bien el desperdicio de alimentos ocurre en los hogares o consumidores finales, la causa tiene su origen en el eslabón anterior de la cadena alimentaria, en este caso, los distribuidores. Como reflexiona STUART, son los distribuidores los que impulsan el desperdicio "hacia abajo", a los consumidores, a través de las ofertas o el empaquetado de los productos $^{13}$.

9 MONDÉJAR-JIMENÉZ, J. A. et al., "From the table to waste: an exploratory study on behaviour towards food waste of Spanish and Italian youths", en Journal of Cleaner Production, núm. 138, 2016, pp. 8-18.

10 StuARt, T. Despilfarro. El escándalo global de la comida, Alianza, Madrid, 2011.

11 Montagut, X. y Gascón, J. Alimentos desperdiciados. Un análisis del derroche alimentario desde la soberanía alimentaria, Icaria, Barcelona, 2014.

12 EVANS, D. "Beyond the throwaway society: ordinary domestic practice and a sociological approach to household food waste", en Sociology, núm. 46, 2011, pp. 41-56; WILLIAMS, H. et al. "Reasons for household food waste with special attention to packaging", en Journal of Cleaner Production, núm. 24, 2013, pp. 141-148; Graham-Rowe, E.; JessoP, D. C. y SPARKS, P., "Identifying motivations and barriers to minimizing household food waste", en Resources, Conservation and Recycling, núm. 84, 2014, pp.15-23.

13 El autor señala que los distribuidores también impulsan el desperdicio "hacia arriba", por ejemplo, cuando compran productos con determinados requerimientos de forma o calibre o al obligarles a producir excedentes para evitar roturas de stocks. STUART, T. Despilfarro..., cit., 
Cuando nos referimos a las causas vinculadas a la demanda, estamos apuntando a las explicaciones que tienen que ver con el propio comportamiento del consumidor. En un informe de la FAO de 2014, se señala que la demanda de los consumidores en relación con la compra de alimentos se ve influenciada por factores psicológicos, culturales y sociales ${ }^{14}$.

Así pues, las conductas de compra en general y, en particular, la compra de alimentos, pueden verse influenciadas por las emociones de los consumidores. El precio puede perder importancia en favor de otros factores que guían la compra de comida. QUINTANILLA distingue entre los conceptos de compra no planificada y compra por impulso ${ }^{15}$. Señala que la primera se produce fuera de una idea prefijada o más allá de una lista previa de los productos a adquirir. El autor destaca que, en el caso de la comida, es posible comprar de forma diferente a lo previsto, porque el consumidor cambia de marca o compra algún producto que había olvidado. Según el mismo autor, la compra por impulso se caracteriza por la fuerte vinculación emocional entre el consumidor y los productos que adquiere. Señala que este tipo de compra depende de la cultura del consumidor, los grupos de referencia a los que pertenece o la situación física o ambiental que vive el consumidor respecto de la oferta comercial. Es la reiteración de la compra compulsiva la que se percibe como perjudicial y, en el caso de la compra de alimentos, ayudaría a explicar el desperdicio alimentario En esta misma dirección se han manifestado Díaz-Ruiz et al. cuando argumentan la importancia del entorno en los comportamientos de los consumidores en su conjunto, así como los propios valores del consumidor en su forma de proceder en el acto de la acción de compra ${ }^{16}$.

Además de las conductas de compra, hay otras causas explicativas del desperdicio en los hogares. El Ministerio de Agricultura, Pesca y Alimentación (MAPA) señala que el desperdicio de alimentos está relacionado con los malos hábitos a la hora de planificar y hacer la compra, así como con una gestión

\footnotetext{
14 FAO, Background paper on the economics of food loss and waste. Working paper, Roma, 2014.

15 Quintanilla, I. Psicología del consumidor, Pearson Educación, Madrid, 2016.

16 Díaz-RuIZ, R. et al. "Moving ahead from food-related behaviours: an alternative approach to understand household food waste generation", en Journal of Cleaner Production, núm. 172, 2018, pp. 1140-1151.
} 
inadecuada de los alimentos ${ }^{17}$. Las rutinas a la hora de comprar o la frecuencia con la que se realiza la compra son también aspectos a considerar. EVANS señala que habitualmente se compra más de lo necesario y se realiza una sobreprovisión de comida ${ }^{18}$. Por el contrario, el desperdicio de alimentos en los hogares es menor cuando las compras se realizan con más frecuencia ${ }^{19}$.

Además de los comportamientos de los hogares a la hora de realizar las compras de comida, cabe mencionar también las prácticas o el cómo se utilizan y se almacenan los alimentos en el hogar. El MAPA considera la gestión inadecuada de los alimentos como una de las causas del desperdicio (incorrecto almacenamiento de la comida, la preparación de grandes porciones o la falta de predicción sobre las pautas de consumo de alimentos de los miembros del hogar $)^{20}$.

Para cerrar este apartado, es debido resaltar el estudio de SCHNEIDER quien correlaciona el desperdicio de alimentos con diferentes variables relativas a las características socioeconómicas de los hogares ${ }^{21}$. Por ejemplo, la gente joven tiende a generar más desperdicio que la gente de más de sesenta años. También se observa que cuanto mayor es el ingreso de la familia, más desperdicio genera. En los países desarrollados, el aumento del poder de compra conlleva que los hogares compren más de lo necesario. A su vez, las familias en las que las personas trabajan a tiempo completo, no planifican tanto las compras de comida y tienden a desperdiciar más cantidad.

\section{El desperdicio de alimentos en la distribución}

Además de los hogares, también las empresas de distribución son responsables del desperdicio alimentario. Según la Agència de Residus de Catalunya tres son las causas explicativas: las tendencias de mercado, las restricciones naturales y

\footnotetext{
17 Ministerio de Agricultura, Pesca y Alimentación, Estrategia "Más alimento, menos desperdicio", 2013.

18 EVANS, D. "Beyond the throwaway society...", cit.

19 WILLIAMS, H. et al. "Reasons for household food waste...", cit.

20 Ministerio de Agricultura, Alimentación y Medio Ambiente, Estrategia "Más alimento, menos desperdicio", cit.

21 SCHNEIDER, F. "Wasting Food. An Insistent Behavior", en Waste-The Social Context' 08. Urban Issues and Solutions. Shaw Conference Centre, May 2008, Edmonton, Alberta, Canadá, 2008.
} 
los tipos de gestión ${ }^{22}$. La primera se refiere a la creciente demanda de productos refrigerados que altera la gestión y duración de los stocks. La segunda tiene que ver con la estacionalidad de la demanda y la duración de los productos frescos. La tercera causa es debida al factor humano (dificultad de predicción de las ventas y control de la cadena de frío durante el transporte de alimentos o deficiencias en el empaquetado). STUART coincide en señalar a las malas previsiones de los responsables de pedidos y a los envases defectuosos como causas explicativas ${ }^{23}$.

Compartimos la idea de que la dificultad en la predicción de las ventas hace que los distribuidores acumulen stocks ya que a los compradores les gustar ver los lineales llenos. MONTAGUT y GASCÓN afirman que los márgenes medios de los supermercados son tan elevados que les sale más rentable tener más productos de los que venderán que arriesgarse a una rotura de stock ${ }^{24}$. En este sentido, se considera que tener las estanterías llenas, hace aumentar las ventas.

Otro de los temas que merece ser comentado es el relativo a las fechas de etiquetado de los productos, un hecho que tiene incidencia sobre los distribuidores y también los hogares. Por un lado, los consumidores suelen interpretar la fecha de consumo preferente como si fuera una fecha de caducidad y tiran comida que supera la primera fecha cuando el producto aún es adecuado para ser consumido ${ }^{25}$.

En un Informe del Tribunal de Cuentas Europeo se señala que "la fecha del etiquetado tiene que ser lo suficientemente clara para que los consumidores eviten alimentos que no sean seguros, así como para prevenir el descarte de productos alimenticios" ${ }^{26}$. Del mismo modo, en el Informe de la Comisión Europea se establece que la información que facilita la etiqueta del producto

22 Agència de Residus de Catalunya, Diagnosi del malbaratament alimentari a Catalunya, Generalitat de Catalunya, 2012.

23 STUART, T. Despilfarro..., cit.

24 MONTAGUT, X. y GASCÓN, J. Alimentos desperdiciados..., cit.

25 Según el Reglamento $n^{\circ} 1169 / 2011$ de la Unión Europea, los productos deben estar etiquetados con la fecha de consumo preferente o bien con la fecha de caducidad. La primera indica la fecha hasta la que el alimento conserva sus propiedades específicas. Los alimentos pueden ser consumidos pasada esta fecha. La fecha de caducidad, en cambio, indica el último día en el que el alimento es seguro.

26 Tribunal de Cuentas Europeo, La lucha contra el despilfarro de alimentos: una oportunidad para la UE de hacer más eficiente el empleo de recursos en la cadena de suministro alimentario, Luxemburgo, 2016. 
induce a confusión y se concluye que el etiquetado de los productos colabora a explicar el desperdicio de alimentos ${ }^{27}$. La Comisión señala que, mediante una política de etiquetado más sencilla se podría reducir el desperdicio de alimentos entre el $15 \%$ y el $33 \%$.

Además del desconocimiento por parte de los hogares, también los distribuidores suelen retirar los productos próximos a las fechas de caducidad o de consumo preferente cuando aún son seguros y aptos para su consumo. MONTAGUT y GASCÓN proponen vender a un precio reducido los productos cercanos a dichas fechas $^{28}$. No obstante, PRIEFER et al. afirman que, en muchos casos, los distribuidores deciden no vender productos que han sobrepasado la fecha de consumo preferente con el objetivo de no dañar su reputación ${ }^{29}$.

\section{EL DESPERDICIO DE ALIMENTOS COMO EXTERNALIDAD ECONÓMICA NEGATIVA: LOS COSTES SOCIALES MEDIOAMBIENTALES DEL DESPERDICIO ALIMENTARIO}

\section{Justificación del desperdicio alimentario como externalidad negativa}

En el ámbito económico, existe una externalidad negativa cuando la producción o el consumo de un bien afectan directamente a empresas o consumidores que no participan en su compra o venta y estos efectos no se reflejan en los precios de mercado. STIGLITZ y ROSENGARD indican que hay una externalidad económica "siempre que una persona o una empresa emprende una acción que produce un efecto en otra persona o en otra empresa por el que esta última no paga ni es pagada"30.

En el caso de las externalidades económicas negativas — también denominadas deseconomías externas- se producen perjuicios derivados del comportamiento

$27 \quad$ Comisión Europea, Market study on date marking and other information provided on food labels and food waste prevention, 2018.

28 MONTAGUt, X. y GASCÓn, J. Alimentos desperdiciados..., cit.

29 PRIEFER, C. et al., "Food waste prevention in Europe-A cause-driven approach to identify the most relevant leverage points for action", en Resources, Conservation and Recycling, vol.109, 2016, pp. 155-165.

30 Stiglitz, J.E. y Rosengard, J.K. La economía del sector público, Antoni Bosch, Barcelona, 2016. 
de consumidores o empresas que otros han de soportar sin recibir compensación por ello. Dichos perjuicios son los denominados costes sociales.

La existencia de externalidades económicas negativas se considera un fallo del mercado puesto que los costes sociales generados no se hallan reflejados en los precios de mercado. Los precios son más bajos de los que resultarían si el valor de las externalidades fuera internalizado; es decir, reflejado en los precios de mercado. En presencia de externalidades, la asignación de bienes basada en el mercado es ineficiente. Así, el nivel de producción suele ser demasiado elevado ya que el productor no tiene en cuenta los costes sociales (por ejemplo, la contaminación que genera). En el caso de externalidades negativas de consumo, el consumidor no tiene en cuenta los costes sociales generados y el consumo tiende a ser más elevado.

El concepto de externalidades económicas negativas puede ser aplicado también al ámbito del desperdicio de alimentos debido a los costes sociales medioambientales que dicho desperdicio genera.

En general, el desperdicio alimentario conlleva costes medioambientales, de entre los cuales destaca la huella de carbono. Este es el término con el que se denomina a la totalidad de gases de efecto invernadero (GEI) emitidos, de entre los cuales, el más conocido y utilizado como referencia es el CO2. Dichos gases se considera que contribuyen al calentamiento global del planeta ${ }^{31}$. En un informe de $2013^{32}$, la FAO analiza el impacto medioambiental del desperdicio y pérdidas de alimentos y estima la huella de carbono en 3.300 millones de toneladas de $\mathrm{CO} 2$ liberadas a la atmósfera. Concluye que, si el despilfarro de alimentos (que incluye las pérdidas y el desperdicio) fuera un país, sería el tercer emisor de gases de efecto invernadero, después de países como Estados Unidos y la China. Otro de los efectos medioambientales que cita la FAO es el consumo de recursos hídricos: la denominada huella de agua o huella hídrica. En este sentido, el volumen de agua utilizada en producir alimentos que acaban en la basura es de $250 \mathrm{~km}^{3}$. La FAO también señala que sólo un pequeño

\footnotetext{
$31 \quad$ Siguiendo a EUROSTAT, la medida de los gases emitidos se realiza en en tCO2eq (volumen de emisión de gases de efecto invernadero equivalente a una tonelada de CO2).

32 FAO, Food wastage footprint, Impacts on Natural resources, Summary report. Roma, 2013.
} 
porcentaje de los alimentos que se tiran van a reciclarse en forma de compost. La mayoría de los alimentos que no se consumen acaban en los vertederos y contribuyen a la emisión de metano. Las emisiones de metano de los vertederos son una de las mayores fuentes de gases efecto invernadero de todo el sector de los residuos.

En el ámbito Europeo ${ }^{33}$, el impacto se estima en 170 toneladas métricas de CO2 equivalente en dióxido de carbono emitidas en Europa y debidas únicamente al desperdicio alimentario en todas sus fases. Se destaca que los impactos se acumulan a lo largo de la cadena de alimentos siendo mayor el impacto ambiental del desperdicio que realizan los hogares. El $46 \%$ de la emisión de gases debida al desperdicio alimentario es atribuible a los hogares. En un informe más reciente ${ }^{34}$ se concluye que la disminución de las pérdidas y desperdicio de alimentos ayudaría a reducir las emisiones de gases de efecto invernadero.

DORWARD destaca el coste medioambiental del desperdicio de alimentos distinguiendo entre el desperdicio en la fase de pre-consumo y el desperdicio en la fase de consumo final (el que realizan las familias, después de la compra) ${ }^{35}$. También CHABOUD y DAVIRON distinguen entre los recursos naturales que se utilizan en vano (como el agua o la tierra) y la contaminación que se produce relacionada con los procesos de gestión de residuos (los productos tirados no desaparecen, se transforman en residuos, generando externalidades negativas) ${ }^{36}$. En el trabajo de CICATIELLO et al. para el caso italiano se calcula el valor medioambiental del desperdicio de alimentos de los supermercados estimando los recursos naturales usados en la producción de alimentos ${ }^{37}$.

A efectos de nuestro trabajo, concluimos que el desperdicio alimentario puede ser concebido como una externalidad económica negativa. En este sentido, el

33 BIO INTELLIGENCE, "Preparatory Study on Food Waste Across EU 27", Comisión Europea, 2010.

${ }^{34}$ IPCC, Intergovernmental Panel on Climate Change. Climate Change and Land. Agosto 2019.

35 DORWARD, L.J. "Where are the best opportunities for reducing greenhouse gas emissions in the food system (including the food chain)? A comment", en Food Policy, vol. 37, 2012, pp. 463-466.

36 ChaBOUD, G. y DAVIRON, B. "Food losses and waste: Navigating the inconsistencies", en Global Food Security, vol. 12, 2017, pp. 1-7.

37 Cicatiello, C. et al., "The value of food waste: An exploratory study on retailing", en Journal of Retailing and Consumer Services, vol. 30, 2016, pp. 96-104. 
desperdicio por parte de consumidores y distribuidores genera importantes costes medioambientales (emisiones de metano de los vertederos donde van los alimentos que no se consumen y tampoco son reciclados y que contribuyen a la generación de gases de efecto invernadero). Dichos costes medioambientales pueden ser considerados como costes sociales, pues son efectos negativos sobre terceras personas o empresas no involucradas en las actividades de consumo o distribución de alimentos. Se trata de una externalidad de consumo cuyos efectos externos impactan, en este caso, sobre toda la sociedad, por ello se puede considerar una externalidad global en donde los causantes de los costes sociales medioambientales no asumen o pagan por el daño causado.

Deberá pues introducirse algún mecanismo corrector para asegurar que los causantes de la contaminación (hogares y empresas de distribución) tengan incentivos para tomar en consideración estos impactos medioambientales al decidir sobre su consumo. Las soluciones teóricas al problema de las externalidades son tratadas en el siguiente apartado.

\section{Soluciones al problema de las externalidades: regulación directa e instrumentos de incentivo económico}

En el ámbito teórico, las soluciones al problema de las externalidades económicas negativas pueden dividirse en soluciones privadas y soluciones basadas en la intervención pública.

En relación con las soluciones privadas, en un artículo de 1960 — «The Problem of Social Cost»-, el economista y premio Nobel Ronald COASE estableció que la solución al problema de las externalidades podía darse mediante acuerdo entre las partes afectadas ${ }^{38}$. Así, según el Teorema de Coase, cuando los derechos de propiedad están bien definidos y los costes de transacción (o de negociación) son pequeños, el problema de las externalidades se puede resolver mediante acuerdo entre las partes. Dicha solución es eficiente e independiente de quién sea el titular de los derechos de propiedad (esto es, de quien tenga legalmente la razón). Según Coase, los costes sociales que generan las externalidades negativas se resuelven mediante negociación privada entre las partes en

38 COASE, R.H. «The Problem of Social Cost», en The Journal of Law and Economics, vol. III, 1960, pp. 1-44. 
conflicto (contaminador y contaminado) y el resultado final es, siempre, una solución negociada. Siguiendo a KRUGMAN Y WELLS, los individuos tienen incentivos para negociar acuerdos que benefician a todas las partes ${ }^{39}$. Dichos acuerdos dan lugar a que los individuos tengan en cuenta las externalidades al tomar sus decisiones, es decir, los agentes internalizan la externalidad.

Para el caso que nos ocupa, es decir, la externalidad negativa en forma de impacto ambiental de los residuos alimentarios, se hace difícil pensar en una solución basada en el Teorema de Coase. Así, a pesar de poder identificar los costes sociales medioambientales, se hace muy complicado trasladarlos a un valor monetario. Es difícil que se alcance un acuerdo privado puesto que el derecho de propiedad no queda claro en este caso. En concreto, no es posible establecer una negociación cuando los perjudicados son decenas de millones de personas que tienen derecho a disfrutar de la atmósfera o la biodiversidad, las cuales pueden ser consideradas como bienes públicos puros. Además, la identificación de las partes en conflicto no está clara. Es difícil identificar los millones de empresas que desperdician y causan contaminación. A su vez, también se hace complicado que los perjudicados sean conscientes de este efecto negativo o externalidad negativa que sufren.

Teniendo en cuenta las dificultades expuestas anteriormente, se hace necesario otro tipo de soluciones, en este caso, desde el ámbito de la intervención pública. Así pues, y desde el punto de vista de la regulación económica, los gobiernos intervienen regulando las actuaciones de empresas y consumidores.

Siguiendo a KOLSTAD ${ }^{40}$, existen dos teorías relativas a la regulación económica: la del interés público y la del grupo de interés. En el primer caso, el propósito de la regulación es promover el interés público. En este caso, la justificación de la regulación gubernamental es la existencia de competencia imperfecta (por ejemplo, monopolios naturales), información imperfecta $y$, finalmente, la existencia de bienes públicos y regulación de externalidades. En el segundo caso, la regulación a favor de grupos de interés, trata de promover los intereses de determinados grupos o industrias. Para el caso de nuestro trabajo nos

39 KRUgman, P. y Wells, R. Microeconomía, Reverté, Barcelona, 2013.

40 KolshTAD, C. D. Economía ambiental, Oxford University Press, México, D.F., 2001. 
interesa la primera de las dos teorías regulatorias y, en concreto, en el ámbito que se refiere a la regulación de externalidades.

La regulación económica basada en el interés público utiliza dos instrumentos regulatorios básicos. En primer lugar, los instrumentos de regulación directa o de "comando y control" y, en segundo lugar, los instrumentos regulatorios de incentivo económico.

Desde un punto de vista teórico, el sector público puede hacer frente al problema de las externalidades negativas a través de la regulación directa (también denominada de "comando y control"), exigiendo o prohibiendo determinadas conductas. Se trata de normas imperativas que regulan la conducta de empresas y consumidores, para que quien genera la externalidad negativa, el contaminador, disminuya el daño causado en el medio ambiente. Algunos ejemplos de este tipo de instrumentos regulatorios son la fijación de límites a la contaminación, como las reglamentaciones relacionadas con los vertidos de sustancias químicas; la exigencia de determinadas tecnologías a las empresas para reducir emisiones contaminantes; o la prohibición de fumar en espacios públicos.

Además de la solución regulatoria, cabe hablar también de los instrumentos regulatorios de incentivo económico. En comparación con las tradicionales regulaciones, el empleo de incentivos económicos trata de provocar cambios en el comportamiento de las empresas y consumidores a través de señales de mercado, ofreciendo unos incentivos determinados de manera que empresas y consumidores internalicen los costes medioambientales de sus actividades, es decir, tengan en cuenta dichos costes en el momento de ejercer las actividades de producción y consumo.

PUIG VENTOSA define los instrumentos económicos basados en el incentivo como "aquellos que persiguen conseguir unos objetivos prefijados favoreciendo o desfavoreciendo económicamente algunas conductas de los agentes de mercado. Así, el cambio de las actitudes sobre las que se quiere incidir se produce no como respuesta a unas normas de obligado cumplimiento, sino porque los sujetos a quienes va dirigido el incentivo adoptan voluntariamente 
acciones que les pasan a ser económicamente más rentables como consecuencia de los incentivos ${ }^{41}$.

Siguiendo a CROPPER y OATES ${ }^{42}$ existen dos grandes tipos de instrumentos de incentivo económico: los que emplean controles de precios (priced-based instruments) y los relativos a incentivos de cantidades o basados en restricciones a las cantidades de emisión de contaminantes (quantity-based instruments) ${ }^{43}$. Los dos se agrupan bajo la denominación de instrumentos basados en el mercado (market-based instruments).

Nuestro interés se centra en los instrumentos de incentivo económico basados en los precios (priced-based instruments), donde el incentivo afecta a los costes de las empresas y por ende a los precios. Estos se pueden dividir en incentivos positivos y negativos. Los incentivos positivos persiguen motivar a las empresas o a los consumidores a realizar determinadas acciones ofreciéndoles para ello una recompensa o gratificación; por ejemplo, mediante beneficios fiscales (tax benefits), subvenciones o los préstamos blandos para, por ejemplo, financiar tecnologías menos contaminantes. Por el contrario, los incentivos negativos promueven o motivan la realización de determinadas acciones a través del castigo o penalización, como el pago de impuestos o de tasas.

En un informe de FUSIONS y, para el caso del desperdicio alimentario, se pone de manifiesto que las experiencias en el uso de estos instrumentos son bastante limitadas puesto que el desperdicio alimentario solo forma parte de las agendas de los gobiernos en los últimos años, en concreto desde 2010. Sin embargo, a su vez señala que este tipo de instrumentos son ampliamente utilizados en otros

$41 \quad$ PUIG VENTOSA, I. "Incentivos económicos para avanzar hacia la reducción y el reciclaje de residuos urbanos", en Revista interdisciplinar de gestión ambiental, núm. 48, 2002, pp. 22-32. 42 CROPPER, M. L. y OATES, W E. "Environmental Economics: A survey", en Journal of Economic Literature, vol. XXX, 1992, pp.675-740.

43 Los instrumentos de incentivo económico basados en cantidades son los denominados derechos o permisos de emisión negociables. Como señalan KRUGMAN y WELLS, dichos derechos autorizan a las empresas a emitir una cantidad máxima de sustancias contaminantes que, además, pueden ser intercambiados por parte de las empresas. KRUGMAN, P. y WELLS, R., Microeconomía, cit.

Según PASCÓ-FONT y MONTOYA se genera un mercado en el cual se realizan transacciones de dichos permisos, a un precio fijado por la oferta y la demanda. Dichos autores presentan seis experiencias relativas al uso de permisos comercializables y otros incentivos económicos para la protección del medio ambiente en el contexto de Estados Unidos, Francia, Alemania y Holanda. PASCÓ-FONT, A. y MONTOYA, A., "Incentivos económicos y protección ambiental: una revisión de la experiencia norteamericana y europea", en Notas para el debate, núm. 11, 1993, pp. 43-60 
campos como el de la contaminación ambiental en general o el tratamiento de residuos sólidos de los hogares ${ }^{44}$. En este sentido, indica que los incentivos que han sido aplicados ampliamente en estos otros campos pueden ser también aplicables al ámbito del desperdicio alimentario, en atención a su importante impacto ambiental.

La regulación directa o de "comando y control" y los instrumentos regulatorios de incentivo económico se hallan presentes en la normativa francesa para solucionar el problema del desperdicio alimentario, a lo que dedicamos el siguiente apartado.

\section{LA NORMATIVA FRANCESA DE LUCHA CONTRA EL DESPERDICIO DE ALIMENTOS: DESCRIPCIÓN Y ANÁLISIS DE LA NORMA DESDE LA PERSPECTIVA DE LA TEORIA DE LAS EXTERNALIDADES}

La preocupación por el desperdicio de alimentos ha llevado a distintos países a regular en esta materia. En el ámbito europeo destaca Francia con la aprobación de varias leyes, entre ellas: la Loi $n^{\circ}$ 2015-992 du 17 août 2015 relative à la transition énergétique pour la croissance verte, la Loi $n^{\circ}$ 2016-138 du 11 février 2016 relative à la lutte contre le gaspillage alimentaire (en adelante, Loi contre le gaspillage alimentaire) y, finalmente, la Loi $n^{\circ}$ 2020-105 du 10 février 2020 relative à la lutte contre le gaspillage et à l'économie circulaire (en adelante, Loi relative à l'économie circulaire) que han modificado distintas normas del ordenamiento jurídico francés con el fin de luchar contra el desperdicio alimentario. Con ellas, la República gala se convirtió en el primer país en legislar mediante una aproximación transversal y multimodal un problema que, como se ha destacado anteriormente, se manifiesta en múltiples dimensiones ${ }^{45}$.

$44 \quad$ FUSIONS, Market-based instruments and other socio-economic incentives enhancing food waste prevention and reduction, 2016.

$45 \quad$ Cuando se aprobó la primera normativa francesa en 2015 y 2016, en Italia existía ya la Legge $n^{\circ} 155$, del Buon Sammaritano, de 25 de junio 2003, la cual no obstante tenía un enfoque unidimensional, preocupándose únicamente por ajustar el régimen de responsabilidad por productos defectuosos con el objetivo de fomentar la donación de alimentos, sin prever otras alternativas al desperdicio. Actualmente, Italia dispone de una nueva Ley con un enfoque mucho más amplio y claramente inspirada en la normativa francesa: La Legge núm. 166, de 19 de agosto de 2016, sobre Disposizioni concernenti la donazione e la distribuzione di prodotti alimentari e farmaceutici a fini di solidarieta' sociale e per la limitazione degli sprechi. En Europa cada vez 
Se trata de una aproximación transversal porque la lucha contra el desperdicio alimentario se aborda tanto desde el Derecho privado como desde el Derecho público. Y, multimodal, porque las medidas legislativas dirigidas a luchar contra el despilfarro son de naturalezas diversas. Esta diversidad se proyecta, de un lado, en la tipología de sujetos a los que se dirigen (involucran a todos los actores de la cadena alimentaria, y también a los consumidores y asociaciones benéficas) y, del otro, en el contenido de las medidas (positivas y negativas).

Las normas francesas incorporan una pluralidad de medidas para luchar contra el desperdicio de alimentos, de entre las cuales destacan por encima del resto: (1) la imposición de una jerarquía de acciones; (2) la prohibición de tirar alimentos; (3) la obligación de donar alimentos, y (4) la responsabilidad social de las empresas ${ }^{46}$.

\section{Imposición de una jerarquía de acciones}

En el artículo L541-15-4 del Code de l'environnement se dice que "[l]a lucha contra el desperdicio de alimentos implica responsabilizar y movilizar a los productores, transformadores y distribuidores de productos alimentarios, a los consumidores y a las asociaciones" ${ }^{\prime 7}$, con lo que se quiere implicar a todos los actores de la cadena alimentaria -productores, trasformadores y distribuidores-, pero también a consumidores y asociaciones en el establecimiento de un conjunto de obligaciones generales para luchar contra el desperdicio de alimentos.

En concreto, se impone a dichos sujetos la siguiente jerarquía de acciones de lucha contra el desperdicio: "1 La prevención del desperdicio de alimentos; $2^{\circ}$ La donación o transformación de los productos sin vender aptos para el consumo

más países cuentan con normas de lucha contra el despilfarro como, por ejemplo, Irlanda e Irlanda del Norte, entre otros.

$46 \quad$ Además de las anteriores, la legislación francesa también tiene en cuenta medidas de sensibilización y educación de los consumidores, así como medidas dirigidas a las Administraciones públicas, o la creación de una etiqueta de lucha contra el despilfarro que puedan utilizar los operadores de la cadena que adopten medidas. También incluye, en línea con la normativa europea, la obligación de medición del desperdicio en relación con ciertos operadores, o medidas vinculadas al etiquetado de los alimentos en relación con la fecha de duración mínima. De estas y el resto de previsiones de la legislación francesa se ocupa en otro lugar: SALAMERO TEIXIDÓ, L. "EI modelo francés de lucha contra el despilfarro de alimentos", en Dereito: revista xurídica da Universidade de Santiago de Compostela, vol. 27, núm.1, 2018.

$47 \quad$ La traducción de los textos de la normativa francesa es nuestra y, por lo tanto, cualquier error o imprecisión es solo atribuible a los autores. 
humano; $3^{\circ} \mathrm{La}$ valorización con destino a la alimentación animal; y $4^{\circ} \mathrm{La}$ utilización para elaborar compost agrícola o la valorización energética, principalmente por metanización". Nótese que la norma francesa no prevé de forma explícita la eliminación.

La priorización francesa se inspira claramente en la legislación medioambiental europea, en la cual el principio de jerarquía se viene recogiendo desde hace tiempo en relación con la prevención y gestión de residuos -en la ya mentada Directiva 2008/98/CE del Parlamento Europeo y del Consejo, de 19 de noviembre de 2008. Así y en especial tras la modificación de la Directiva Marco de Residuos para incorporar el concepto de "residuo alimentario", encaja sin fisuras que la legislación francesa traslade la jerarquía de residuos en la lucha contra el despilfarro de alimentos.

Vista la relación de sujetos y de medidas jerarquizadas, queda por dilucidar cuál es el alcance de la priorización del artículo L544-15-4 del Code de l'environnement. El tenor literal del precepto configura la priorización como un conjunto de obligaciones dirigidas a los distintos sujetos de la cadena alimentaria. Ahora bien, la eficacia de dichas obligaciones depende de su eventual concreción en otros preceptos del mismo Código u otras normas. Por ejemplo, la obligación de donar alimentos viene recogida en preceptos posteriores del Código de medioambiente, regulándose de forma concreta cómo debe articularse dicha obligación y qué consecuencias tiene su incumplimiento.

\section{Prohibición de tirar alimentos}

Una de las previsiones más contundentes de la regulación francesa es la prohibición de desechar alimentos aptos para el consumo humano. Dicha previsión está contenida en el art. L541-15-5 del Code de l'environnement, según la modificación operada por la Loi contre le gaspillage alimentaire de 2016 y la Loi relative à l'économie circulaire de 2020.

Dicho precepto contiene dos previsiones dirigidas a evitar que la comida se tire. Así, el apartado primero del artículo L541-15-5 del Code de l'environnement establece que: "Los distribuidores del sector alimentario, los mayoristas, los operadores de la industria alimentaria que producen alimentos que se distribuyan al sector minorista y los operadores de restauración colectiva asegurarán la 
comercialización de sus productos alimentarios o su valorización conforme al orden de prioridades establecidas en el artículo L541-15-4". Si bien inicialmente la norma solo se refería a los distribuidores - cuestión en su momento criticada por la doctrina-, la reciente modificación realizada en 2020 mediante la Loi relative à l'économie circulaire incluye a otros agentes de la cadena alimentaria, aunque se excluye a los consumidores.

Seguidamente en el precepto se dice que: "Sin perjuicio de la normativa en materia de seguridad alimentaria, no podrán calificar deliberadamente sus productos sin vender pero todavía consumibles, como productos no aptos para el consumo o para cualquiera de las formas de valorización previstas en el artículo L. 541-15-4". La ley obliga así a los distribuidores a gestionar tales productos con pleno sometimiento a la jerarquía establecida, al prohibir que se tiren los alimentos inocuos que puedan ser destinados al consumo humano o a cualquiera de las otras finalidades de la jerarquía para su reutilización, reciclaje o valorización.

Con esta prohibición se pretende evitar la javellisation, una conducta habitual consistente en rociar con lejía (eau de javel, en francés) alimentos que, a pesar de ser aptos para el consumo humano, son desechados por los distribuidores porque, por ejemplo, el envase está dañado, el alimento está próximo a la fecha de caducidad o ha superado la fecha de duración mínima, etc. La javellisation evita al productor y al distribuidor que el producto se consuma y, así, tener que asumir eventuales responsabilidades. Asimismo, se prevé que el incumplimiento de tales obligaciones se castigue con penas iguales al $1 \%$ de la cifra de negocios del último ejercicio.

\section{La obligación de donar alimentos}

Una de las principales medidas previstas en la normativa francesa es la donación de alimentos. La regulación de la donación, contenida en el art. L541-15-6 del Código de Medioambiente junto a otras normas, tiene dos objetivos principales. De un lado, dotar de la mayor seguridad jurídica la donación de alimentos (práctica que informalmente ya venía realizándose). $Y$, del otro y con carácter principal, remover los obstáculos que puedan entorpecer la donación de alimentos aptos para el consumo humano. 
El grueso de la regulación de la donación recae en su imposición. En este aspecto, si bien la norma inicialmente solo obligaba a las superficies de distribución de alimentos al por menor superiores a $400 \mathrm{~m}^{2}$, tras la modificación de 2020 de la Loi relative à l'économie circulaire, el abanico de sujetos obligados a realizar tales donaciones se amplía considerablemente. Así, actualmente, los sujetos obligados son, además de las mentadas superficies, todos los operadores de la industria alimentaria mencionados en el art. L541-15-5, cuyo beneficio anual supere los 50 millones de euros; los servicios de restauración colectiva que sirvan más de 3000 comidas al día; y los mayoristas alimentarios con un beneficio anual superior a los 50 millones de euros. Los operadores obligados no solo son los que supuestamente generan más despilfarro en atención al volumen de negocio, sino también porque se asume que dispondrán de más medios para articular tales donaciones. Junto a lo anterior, la norma recoge que las superficies comerciales de superficie inferior a los 400m2 y vendedores ambulantes y servicios de cáterin podrán potestativamente realizar tales donaciones.

La imposición de donar es inmediata, en tanto que la ley obliga no a la donación sino a formalizar un pacto o convenio que regule dicha donación a organizaciones benéficas (art. L541-15-6, párrafo primero, del Código de Medio Ambiente). Es preciso notar que no podrá donarse a cualquier sujeto —por ejemplo, directamente a consumidores finales-, sino únicamente a personas jurídicas de Derecho público o de Derecho privado habilitadas por la autoridad competente, con el objetivo de evitar que los alimentos donados se destinen a fines distintos o que se cree un mercado alternativo con ellos.

Por último, la regulación francesa, como es obvio, restringe la donación solo a los alimentos seguros; y prohíbe que contractualmente se impida donar los productos con marca del distribuidor; y además establece el incumplimiento de dicha obligación como una infracción de las más graves (de la $5^{\circ}$ clase) que puede ser sancionada con una considerable multa (art. L541-15-6 párrafo V del Código de Medio Ambiente). Es preciso resaltar que la conducta que se sanciona es el no formalizar convenios de donación y solo indirectamente, pues, el hecho de que no se done. 
Las anteriores no son las únicas medidas que la legislación francesa prevé en relación con la donación de alimentos. También la normativa fiscal tiene en cuenta que los tributos pueden suponer una traba, de modo que existen algunos ajustes susceptibles de estimular la donación de alimentos. En concreto dos son los impuestos que entran en juego en el acto de la donación: de un lado, el impuesto sobre el valor añadido (IVA) y, del otro, el impuesto de sociedades. La legislación francesa no contempla ninguna previsión aplicable al IVA vinculado a la donación de alimentos, pero sí que incide en el impuesto de sociedades.

En este sentido, interesa el artículo 238 bis del Code Général des Impôts, que pretende estimular actuaciones de mecenazgo al contemplar que las donaciones dinerarias o en especie puedan suponer una minoración del importe a satisfacer del impuesto sobre la renta o del impuesto de sociedades. Así, se regula que el $60 \%$ del valor neto de la donación pueda deducirse de dichos impuestos, con el límite de 10.000 euros o del cinco por mil de la cifra total de negocios cuando dicho importe sea mayor, en los casos en los que la donación se realice a una serie de entidades benéficas, sin fines de lucro, etc. Esta es una previsión de carácter general de estímulo del mecenazgo que, aunque no esté explícitamente dirigida a la donación de alimentos, puede perfectamente aplicarse al caso ${ }^{48}$.

\section{Responsabilidad social de las empresas}

La Loi contre le gaspillage alimentaire, en su artículo 4, también ha previsto la modificación del Código de Comercio francés para acoger como uno de los ámbitos de la responsabilidad social de las empresas la lucha contra el desperdicio de alimentos. En virtud de dicha modificación el art. L 225-102-1 del Code de Commerce reza actualmente que en el informe anual que presentarán los consejos de administración o dirección empresarial a la asamblea general deberá constar, entre otros, información relativa a la "lucha contra el desperdicio de alimentos" y, también "contra la precariedad alimentaria". Se incorpora así de forma explícita al texto de la ley el desperdicio de alimentos como un posible

$48 \quad$ Así se pone de manifiesto en el documento elaborado por la Direction Générale des Finances Publiques comentando e interpretando la legislación fiscal francesa, en el que se considera de forma específica la donación de alimentos. Vid. Bulletin Officiel des Finances Publiques-Impôts el 7 de febrero de 2017: "BIC - Réductions d'impôts - Mécénat ou réduction d'impôt pour les dons en faveur des œuvres et organismes visés à l'article 238 bis du CGI Conditions relatives aux versements effectués par les entreprises" (BOI-BIC-RICI-20-30-10-2020170207). 
contenido de la responsabilidad social corporativa. El mandato va especialmente dirigido a las empresas que forman parte del sector alimentario, pero no han de excluirse otras empresas u organizaciones.

\section{Las medidas del gobierno francés en el contexto de la teoría de las externalidades}

Como se ha señalado en el apartado anterior, la regulación directa es un importante instrumento en el marco de la teoría de las externalidades dirigido al objetivo de reducir el desperdicio alimentario. En este sentido, la norma francesa establece como una de sus medidas principales la donación de alimentos. Junto a la obligatoriedad de donar también se establece la prohibición de tirar alimentos todavía aptos para el consumo humano. En el marco de la teoría de las externalidades, ambas medidas pueden ser consideradas como ejemplos de regulación directa o normas de comando y control, de obligado cumplimiento para las empresas que van destinadas a regular la conducta de dichas empresas y resolver el problema del desperdicio y sus costes sociales medioambientales asociados.

La regulación directa es manifestación del compromiso por parte del legislador francés respecto de la reducción del desperdicio. La donación permite trasladar una parte del costo del desperdicio de alimentos a las organizaciones benéficas, quienes asumen los costes derivados de la clasificación, almacenamiento y tratamiento de alimentos donados ${ }^{49}$. No obstante, como ya se ha señalado, cabe tener en cuenta el Impuesto sobre el Valor Añadido (IVA). En este sentido, las empresas donantes dejan de repercutir el IVA de los alimentos ya que, a pesar de seguir pagándolo al proveedor, no lo pueden recuperar.

La eficacia de una medida regulatoria como la que establece el legislador francés, depende del cumplimiento de la obligación de donar y del respeto a la prohibición de tirar. Esto exige, en ambos casos, el establecimiento de multas o penalizaciones para las empresas no cumplidoras, tal como hace en ambos casos la normativa gala.

49 Tribunal de Cuentas Europeo, La lucha contra el despilfarro de alimentos: una oportunidad para la UE de hacer más eficiente el empleo de recursos en la cadena de suministro alimentario, Luxemburgo, 2016. 
Además de las normas de regulación directa, los instrumentos regulatorios de incentivo económico son otra de las soluciones al problema de las externalidades negativas. En su informe, FUSIONS utiliza precisamente el caso francés como ejemplo de instrumento (basado en el mercado) de incentivo positivo ${ }^{50}$. Como se recordará, la norma francesa establece que las empresas que efectúan donaciones pueden desgravar en el impuesto sobre la renta o en el impuesto de sociedades, el $60 \%$ del valor neto de la donación, tomando como referencia su precio de coste. Se trata de un incentivo positivo y, en concreto, de un beneficio fiscal y, dentro de este tipo de incentivos, de una desgravación fiscal que busca cambiar el comportamiento de las empresas del sector alimentario.

Entendemos que la desgravación fiscal tiene un efecto incentivador, es decir, estimula el cambio de comportamiento de las empresas, de modo que el desperdicio sea menor del que se hubiera producido de no existir la desgravación. Como resultado, serán menores los impactos medioambientales.

La donación conlleva un efecto positivo para las empresas distribuidoras y redunda en un menor desperdicio e impacto ambiental. Además, su puesta en práctica despliega un efecto positivo adicional para el grupo social y, en concreto, para los receptores finales de la comida (hogares con bajo poder de compra que necesitan ser ayudados por las entidades benéficas).

En este sentido, la donación de los excedentes de alimentos a las entidades benéficas puede reportar a las empresas la aprobación pública teniendo en cuenta la creciente preocupación social por el tema del desperdicio de alimentos. Así, la donación puede ser vista como parte de la Responsabilidad Social Corporativa o Empresarial (RSE) y ser valorada favorablemente por parte de los clientes que apreciarán la reputación e imagen pública de la empresa ${ }^{51}$.

$50 \quad$ FUSIONS, Market-based instruments and other socio-economic incentives enhancing food waste prevention and reduction, 2016.

51 Según CASTRO, la gestión de la RSE "supone el reconocimiento de las preocupaciones sociales, laborales, medioambientales y de respeto a los derechos humanos, en la gestión de la empresa, de forma que se generen políticas, estrategias, decisiones y procedimientos que satisfagan dichas preocupaciones y configuren sus relaciones, de forma transparente, con sus interlocutores". CASTRO, M., "La Responsabilidad Social de las Empresas, o un nuevo concepto de empresa", en Revista CIRIEC, núm. 53, 2005, pp. 29-51.

Según YERA y PIN, "(...) la RSE se muestra como un acto de responsabilidad de las consecuencias que se desprenden de las propias actividades de las empresas". YERA, T. y PIN 
A pesar de que el objetivo de las empresas es la maximización del beneficio económico, también deben asumir responsabilidades por el impacto que sus decisiones y actividades generan, por ejemplo, en el medio ambiente. El desperdicio de alimentos que realizan tiene un claro impacto ambiental y es adecuado pues, que las empresas incluyan este tema en su RSE. El modelo francés ha sido pionero en este sentido puesto que la norma francesa establece que el desperdicio alimentario forme parte del contenido de sus informes anuales.

\section{PROPUESTAS AL PROBLEMA DEL IMPACTO AMBIENTAL DEL DESPERDICIO ALIMENTARIO}

\section{Actual marco normativo sobre el desperdicio alimentario en España}

España no cuenta todavía, a diferencia de Francia, con ninguna norma estatal que haga frente de forma específica al desperdicio alimentario. La dificultad de articular un texto normativo que aborde el desperdicio alimentario radica, entre otros, en la multitud de materias que confluyen en este tema.

Si bien la dimensión medioambiental del desperdicio es clara — como plasma la Directiva Marco de Residuos-, también son relevantes aspectos que se conectan con cuestiones tributarias, como el impuesto sobre el valor añadido o el impuesto de sociedades; cuestiones vinculadas al derecho civil y mercantil, como la regulación de la donación y las responsabilidades vinculadas a la misma, o la responsabilidad social corporativa; o elementos vinculados a salud pública y la seguridad alimentaria, como es obvio. Pero, sobre todo, se añade a lo anterior la estructura autonómica de nuestro país, con un complejo reparto competencial entre Estado y Comunidades Autónomas, además del nivel local, lo cual acrecienta la dificultad de estructurar normativamente un único texto en el que tengan cabida todas las posibles dimensiones de este problema ${ }^{52}$.

J.R., La Demanda Social de la Responsabilidad Pública. Marco de referencia sobre RSC y buen gobierno, IESE Business School, Universidad de Navarra, 2010.

52 No obstante, debe darse cuenta de distintas iniciativas en sede parlamentaria. En 2015 y 2016, respectivamente, el Grupo Parlamentario Mixto presentó sendas Proposiciones no de ley sobre la prohibición de tirar alimentos aptos para el consumo humano y la reducción del despilfarro alimentario (161/003767), y sobre la lucha contra el desperdicio alimentario (161/000227), sin que ninguna de las dos prosperara. En 2017, el Grupo Parlamentario Socialista presentó otra Proposición no de Ley sobre medidas para combatir el despilfarro alimentario (161/001580). El Grupo Parlamentario del Partido Popular ha centrado su atención en la 
En relación con la dimensión medioambiental del desperdicio alimentario y su comprensión como residuo, debe traerse a colación la Ley 22/2011, de 28 de julio, de residuos y suelos contaminados, norma de carácter básico, así como la normativa autonómica aprobada en desarrollo de tales bases $^{53}$. Igualmente, tiene un papel destacado la normativa local, pues la recogida, gestión y tratamiento de residuos es una las pocas competencias propias de los entes locales que todavía se conciben como un servicio público (arts. 25.2.b y 86.2 respectivamente de la Ley 7/1985, de 2 de abril, Reguladora de las Bases del Régimen Local).

Junto a las anteriores normas, y todavía en relación con los residuos, en España rige con carácter general el Plan Estatal Marco de Gestión de Residuos (PEMAR) 2016-2022, en cuyo seno el residuo alimentario ocupa un lugar secundario, como parte de los residuos orgánicos. No obstante, debe ponerse en relieve la existencia de la Estrategia "Más alimento, menos desperdicio". Programa para la reducción de las pérdidas y el desperdicio alimentario y la valorización de los alimentos desechados 2017-2020, aprobada en 2013 y renovada en $2017^{54}$, del Ministerio de Agricultura, Pesca y Alimentación (MAPA). Se trata de un instrumento de programación -y por lo tanto carece de naturaleza normativa-

donación de alimentos y presentó en 2017 una Proposición de Ley para promover y facilitar la donación de alimentos (122/000106) y una Proposición no de Ley sobre el IVA aplicado a la donación de alimentos (161/001992). Finalmente, en 2018, el Grupo parlamentario de Ciudadanos presentó una nueva Proposición no de Ley sobre medidas para reducir el desperdicio alimentario (161/003601). Iniciativas ha habido y se dan, pero los últimos tiempos convulsos, impiden el avance de las mismas; de momento, ninguna ha llegado a buen puerto.

$53 \quad$ En Andalucía, la Ley $7 / 2007$, de 9 de julio de Gestión Integrada de la Calidad Ambiental; en Baleares, la Ley 8/2019, de 19 de febrero, de residuos y suelos contaminados de las llles Balears; en Canarias, la Ley 1/1999, de 29 de enero, de residuos de Canarias; en Cantabria, la Ley 8/1993, de 18 de noviembre, del Plan de Gestión de Residuos Sólidos Urbanos de Cantabria;; en Cataluña, el Decreto Legislativo 1/2009, de 21 de julio, por el que se aprueba el Texto refundido de la Ley reguladora de los residuos; en Galicia, la Ley 10/2008, de 3 de noviembre, de residuos de Galicia; en Madrid, la Ley 5/2003, de 20 de marzo, de Residuos de la Comunidad de Madrid; en Navarra, la Ley Foral 14/2018, de 18 de junio, de Residuos y su Fiscalidad, sin perjuicio de la Ley Foral $7 / 2013$, de 25 de febrero, sobre utilización de residuos alimenticios; en el País Vasco, la Ley 3/1998, de 27 de febrero, General de Protección del Medio Ambiente del País Vasco; y en Valencia, la Ley 10/2000, de 12 de diciembre, de residuos de la Comunidad Valenciana. Decreto 19/2019, de 26 de marzo, por el que se promueven medidas para evitar el desperdicio alimentario y se facilita la redistribución de alimentos en Castilla-La Mancha

54 Puede accederse al documento en el siguiente enlace: http://menosdesperdicio.es/sites/default/files/documentos/relacionados/estrategia 17-20.pdf 
de carácter específico en materia de desperdicio alimentario y dentro de la cual se desarrollan distintos tipos de acciones.

Este grupo normativo y de planificación se verá necesariamente afectado con la entrada en vigor de las ya comentadas medidas de la DMR en materia de residuos alimentarios: esencialmente, la imposición de la separación de los residuos orgánicos, y obligaciones de medición de los residuos alimentarios ${ }^{55}$. También entendemos que son estas normas medioambientales las más apropiadas para acoger la regulación de obligaciones vinculadas al desperdicio alimentario, entendido como una cuestión de prevención y gestión de los residuos alimentarios según la jerarquía de residuos, tal como ha hecho la república gala. Así, también, como estrategia de prevención, encaja en este marco normativo estatal básico la imposición de la donación de aquellos alimentos que, no vayan a ser destinados a la venta, pero que todavía sean seguros, tal como se ha hecho en Francia. La lectura de estas normas medioambientales arroja en ocasiones previsiones que tienen en cuenta el desperdicio de alimentos ${ }^{56}$.

En relación con las normas estatales susceptibles de generar impacto en materia de desperdicio alimentario es preciso traer a colación también normas vinculadas al ámbito empresarial, y tributarias. En cuanto a la legislación mercantil y, en concreto, el Código de Comercio en cuyo artículo 49 se prevé que en el informe de gestión consolidado se dé cuenta de "acciones para combatir el desperdicio de alimentos" 57 ; nada más dice dicho Código ni otras normas vinculadas a las sociedades mercantiles en relación con los informes anuales de gestión y la plasmación de estos aspectos vinculados a la responsabilidad social y el desperdicio alimentario.

55 El Ministerio de Agricultura y Pesca, Alimentación y Medio Ambiente ha elaborado un borrador de anteproyecto de ley por la que se modifica la Ley 22/2011, de 28 de julio, de residuos y suelos contaminados, que propone una nueva redacción del artículo 24 de la Ley, sobre los biorresiduos. Puede consultarse el anteproyecto en la web del Ministerio, en el siguiente enlace: https://www.miteco.gob.es/images/es/borradoraplmodificacionleyderesiduos20180518_tcm30449600.pdf

$56 \quad$ Entre otras la misma Ley estatal básica, en su anexo IV, apartado 19, donde recoge propuestas para reducir el despilfarro de alimentos.

57 En virtud de la modificación operada por la Ley 11/2018, de 28 de diciembre, por la que se modifica el Código de Comercio (...). 
En cuanto al ámbito tributario, guarda silencio la Ley 37/1992, de 28 de diciembre, del Impuesto sobre el Valor Añadido, que no regula ningún reducción, exención o modulación de la base imponible de alimentos donados. En cambio, en relación con el impuesto sobre sociedades, si bien la Ley 27/2014, de 27 de noviembre, del Impuesto sobre Sociedades, guarda también silencio al respecto, la Ley 49/2002, de 23 de diciembre, de Régimen fiscal de las entidades sin fines lucrativos y de los incentivos fiscales al mecenazgo (en adelante, Ley del Mecenazgo) establece una medida similar a la francesa. En virtud de los artículos 17, 18 y 20 de la Ley del Mecenazgo, los sujetos pasivos del impuesto sobre sociedades tendrán derecho a deducir de la cuota íntegra un $35 \%$ del valor de los bienes donados según el valor contable que tuviesen en el momento de la transmisión, cuando la donación sea realizada a entidades sin fines lucrativos, entre otros.

Por cuanto a las Comunidades Autónomas, a diferencia de las cortes centrales, algunas de ellas ya han aprobado normativa en la que se tiene en cuenta del desperdicio alimentario. En este sentido, la Comunidad Foral Navarra fue pionera al aprobar la Ley $7 / 2013$, de 25 de febrero, de utilización de residuos alimenticios de Navarra, para favorecer la distribución de alimentos aptos para el consumo, aunque no comercializables, a los bancos de alimentos $u$ organismos análogos. En Murcia cuentan con la Ley 10/2013, de 18 de octubre, para el aprovechamiento de excedentes alimentarios y creación de la Red Solidaria para el Aprovechamiento de Alimentos. En Baleares se ha aprobado recientemente la Ley 8/2019, de 19 de febrero de Residuos y Suelos Contaminados, plagada de buenas intenciones, y que fija el objetivo de reducir en un $50 \%$ el desperdicio de alimentos entre 2020 y 2030, con obligaciones esencialmente dirigidas al gobierno balear. En Castilla-La Mancha se ha aprobado la Ley $7 / 2019$, de 29 de noviembre, de Economía Circular que incluye entre sus objetivos la reducción del desperdicio alimentario, así como el Decreto 19/2019, de 26 de marzo, por el que se promueven medidas para evitar el desperdicio alimentario y se facilita la redistribución de alimentos, que cuenta con un código de buenas prácticas y medidas dirigidas a todos los actores de la cadena. Cantabria destaca porque es la única comunidad autónoma que cuenta 
con una estrategia específica contra el despilfarro de alimentos, aprobada por el Decreto 56/2019, de 11 de abril. Y, por último, la última en sumarse ha sido Cataluña, con la Ley 3/2020, de 11 de marzo, de prevención de las pérdidas y el despilfarro alimentarios, que si bien cuenta con un buen número de obligaciones -e incluso un cuadro de sanciones e infracciones-, pero su configuración es en ocasiones muy genérica y, en otras, repetición de lo que ya se establece en la normativa sobre residuos, higiene y seguridad alimentaria. No obstante, destaca el establecimiento de una jerarquía para la prevención y gestión en materia de alimentos, y algunas específicas obligaciones dirigidas a los operadores.

Las normas autonómicas, en general, si bien ambiciosas en sus objetivos y propuestas, en muchas ocasiones se basan en recomendaciones y futuros desarrollos reglamentarios; todo ello sin perjuicio de algunas medidas efectivamente dirigidas a la prevención del desperdicio de alimentos que también recogen; en este sentido destacan especialmente las normas manchega y catalana.

\section{Propuestas en atención al modelo francés}

La obligatoriedad de formalizar pactos o acuerdos que regulen la donación de los excedentes alimentarios a entidades benéficas bajo pena de sanción en caso de incumplimiento constituye una de las medidas centrales del modelo francés. A dicha medida cabe añadir también, como se ha comentado anteriormente, la prohibición de tirar alimentos aptos para el consumo humano.

Creemos que la normativa española debe acoger de forma específica la donación de alimentos por parte de los distribuidores a bancos de alimentos $u$ organismos análogos. En este sentido, debería obligarse a los distribuidores a separar los alimentos todavía aptos para su consumo pero que van a ser desechados, del resto de los residuos y, en particular, del resto de los residuos orgánicos. El establecimiento de acuerdos regulados por ley entre distribuidores y bancos de alimentos permitiría dar una salida a estos excedentes de alimento. Junto a lo anterior, la prohibición expresa de tirar alimentos aptos para ser consumidos es también una interesante propuesta que, al igual que en el modelo francés, deberían recoger la legislación patria. 
Entendemos que este tipo de regulaciones encajan en el marco normativo medioambiental, en concreto en las normas vinculadas a la prevención de gestión y de prevención de residuos; marco legislativo básico y cuyo desarrollo y ejecución se traslada a las comunidades autónomas. La próxima transposición de la DMR —-primero con la incorporación del nuevo concepto de "residuo alimentario", y después con la obligación de separar los biorresiduos y la de medir los residuos alimentarios generados - ofrece una buena oportunidad para ello.

En la actualidad, la donación de alimentos es una práctica habitual de distribuidores que ha sido promovida por las políticas públicas con el objetivo de paliar la pobreza, especialmente en los años de la crisis económica. Los receptores, principalmente, bancos de alimentos $y$, por ende, las personas beneficiarias, se han servido de su efecto positivo desde el punto de vista social.

En este sentido, proponemos que la normativa sea sensible al problema del desperdicio de alimentos e incluya instrumentos de incentivo positivo, en concreto, beneficios fiscales. Además del incentivo que prevé la Ley del Mecenazgo con carácter general a las donaciones; entendemos que otros incentivos específicos en relación con el impuesto de sociedades y, en especial, el impuesto al valor añadido, serían eficaces en la lucha contra el desperdicio.

Finalmente, como cierre a este conjunto de estímulos, creemos que el desperdicio de alimentos debería formar parte de la responsabilidad social corporativa o empresarial, de modo que las empresas distribuidoras deberían incluir este aspecto en sus informes anuales de rendición de cuentas. La legislación mercantil debería ajustarse en este sentido. Como señala SALAMERO, imponer de forma específica el desperdicio alimentario como parte de la RSE ofrece a las empresas la posibilidad de reflexionar acerca de su papel en la lucha contra el desperdicio de alimentos ${ }^{58}$.

\footnotetext{
$58 \quad$ La autora propone que esta sea una práctica habitual de las empresas, siguiendo el ejemplo francés, donde se modificó el Código de Comercio de forma expresa para que el desperdicio alimentario forme parte de la RSE. SALAMERO TEIXIDÓ, L. "El desperdicio de alimentos", en SAlamero TeIXIDÓ, L. (dir.) Manual básico de Derecho alimentario, Tirant Lo Blanch, Valencia, 2019.
} 


\section{El pago por generación: otra propuesta basada en los instrumentos de} incentivo económico

a) Concepto de pago por generación

Como se ha visto en los apartados anteriores, la norma francesa ha optado por la opción regulatoria y el uso de instrumentos de incentivo positivo, en concreto beneficios fiscales. A pesar de no estar contenidos en la regulación francesa, existen otro tipo de propuestas para reducir el problema ambiental del desperdicio alimentario a las que vamos a hacer referencia en este apartado.

Como contraposición a los instrumentos de incentivo positivo, existen los denominados instrumentos de incentivo negativo, los cuales persiguen motivar determinadas acciones —en nuestro caso, reducir y prevenir el desperdicio de alimentos- a través del pago de determinados impuestos o tasas.

Desde el ámbito teórico, una de las soluciones al problema de las externalidades ambientales es el establecimiento de impuestos. Los impuestos pigouvianos ${ }^{59}$ obligan a las empresas que contaminan a pagar un impuesto que depende de la cantidad de contaminación que generan (pago por unidad de contaminación producida), con lo que la empresa se ve obligada a reducir las actividades contaminantes. Se trata de un instrumento de incentivo económico basado en el mercado que modifica el comportamiento de empresas y consumidores de manera que se internalizan los costes ambientales. Estos impuestos forman parte del denominado principio de quien contamina paga (polluter pays principle) o principio del contaminador pagador.

Según el polluter pays principle, el responsable de generar la contaminación es también responsable de pagar en proporción al daño causado al medio ambiente. Así, sobre la base de este principio, el sujeto pasivo es la persona física o jurídica que emprende o realiza la actividad que genera contaminación. La idea básica es que el precio de los bienes y servicios debe reflejar los costes totales para la empresa, incluyendo los costes sociales medioambientales generados. Sin embargo, uno de los problemas principales es el de determinar

\footnotetext{
$59 \quad$ En honor del economista PIGou, que en 1920 estableció la utilidad de dichos impuestos para la corrección de externalidades en su libro titulado La Economía del Bienestar. PIGOU, A.C. The Economics of Welfare, Palgrave Macmillan, 2013.
} 
el valor de dicho impuesto, en concreto, la medición de la base imponible, puesto que ésta depende de la magnitud del daño causado al medio ambiente.

El principio del contaminador pagador ha sido aplicado a la gestión de residuos en el ámbito municipal. En este caso, el instrumento utilizado se basa en el principio pay-as-you-throw o paga en función de lo que tires o pago por generación (en adelante, PAYT), aplicado al caso de los residuos generados por empresas y hogares. Existen dos modalidades principales de PAYT: el pay-byvolume, pago por volumen; y el pay-by-weight, pago por peso ${ }^{60}$. En el primer caso, el ciudadano o empresa paga en función del volumen de los residuos, que se controla a través de bolsas, adhesivos, contenedores con tamaños preestablecidos, u otros mecanismos. El sistema de pago por peso es más exigente a nivel técnico puesto que requiere vehículos de recolección equipados para pesar los residuos ${ }^{61}$.

Estados Unidos ha sido un país pionero por lo que se refiere a los sistemas de pago por generación. Según un informe del Programa Medioambiental de la FAO, el PAYT se ha implementado, además de en Estados Unidos, en países como Suecia, Canadá, Japón, Taiwan, Corea, Tailandia, Vietnam y China ${ }^{62}$, o España ${ }^{63}$. Según FUSIONS, el PAYT es un principio básico de las políticas de gestión de residuos por parte de los consumidores y empresas y está siendo aplicado en diversos Estados de la Unión Europea ${ }^{64}$.

$60 \quad$ Para una aproximación comprensiva a estos impuestos puede verse el informe de la EPA (United States Environmental Protection Agency), Pay-As-You-Throw. Lessons Learned about Unit Pricing, 1994; o PUIG VENTOSA, I. "Incentivos económicos para avanzar hacia la reducción y el reciclaje de residuos urbanos", en Revista interdisciplinar de gestión ambiental, núm. 48, 2002, pp. 22-32.

61 Las principales alternativas para la implementación de los sistemas de pago por generación (PAYT) se dividen en sistemas basados en la identificación del usuario y los basados en la identificación del recipiente. Ambos se subdividen en sistemas de pago por volumen o pago por peso. Sobre el tema de los sistemas para implementar el PAYT, puede consultarse el trabajo de Reichenbach, J., "Status and prospects of pay-as-you-throw in Europe_A review of pilot research and implementation studies", en Waste Management, 28, 2008, pp. $2809-2814$.

62 UNEP (United Nations Environment Programme, FAO), Prevention and Reduction of Food and Drink Waste in Businesses and Households: Guidance for Governments, Local Authorities, Businesses and Other organizations. Version 1.0, 2014.

63 Entre otros, puede verse el trabajo de Ignasi PUIG VENTOSA, "Charging systems and PAYT experiences for waste management in Spain”, en Waste Management, núm. 28, 2008, p. 2767-2771, sobre la experiencia de pago por bolsa en el municipio catalán de Torrelles de Llobregat para el caso de la fracción inorgánica y que estuvo vigente entre enero y septiembre del año 2003.

$64 \quad$ FUSIONS, Market-based instruments..., cit. 
Los sistemas PAYT tienen efectos positivos ya que favorecen el reciclaje de los residuos. Como las familias y empresas son gravadas en función de los residuos que generan, ello conduce a un aumento del reciclaje y la prevención (generar menos residuos). En Estados Unidos, por ejemplo, se señala los beneficios potenciales del sistema PAYT en las localidades que han adoptado estos programas, por ejemplo, la reducción de los residuos generados o los cambios en el comportamiento de los residentes modificando sus patrones de compra y consumo para reducir los residuos o el mayor conocimiento de los individuos sobre el impacto ambiental de los residuos lo que lleva a minimizarlos ${ }^{65}$. En el contexto europeo, para servirnos de otro ejemplo, utilizando el caso de Suecia, la doctrina detalla las fortalezas y debilidades del sistema del PAYT (en concreto, el pago por peso) en el ámbito local. Los estudios muestran que los municipios con esquemas de pago por peso recogen un $20 \%$ menos de residuos de las familias por habitante, en comparación con el resto de municipios ${ }^{66}$.

A pesar de sus beneficios, no pueden obviarse las críticas a estos sistemas, las cuales apuntan que pueden favorecer que los residuos acaben en vertederos ilegales o en municipios que no tienen implantados estos sistemas ${ }^{67}$. Además de los vertidos ilegales, se señala también la resistencia al cambio de la ciudadanía, la cual requiere programas públicos educativos para informar a la población sobre los costes económicos y medioambientales de la generación de residuos $^{68}$.

\section{b) Aplicación al caso del desperdicio alimentario}

Los esquemas anteriores basados en el principio del PAYT pueden ser aplicados en el ámbito de los residuos urbanos municipales para la fracción orgánica, en la cual se incluyen los residuos alimentarios. De hecho, el Parlamento Europeo se refiere a "medidas coercitivas contra el desperdicio de alimentos" e introduce también el principio del contaminador pagador cuando señala "que se adopte

\footnotetext{
65 EPA, Pay-As-You-Throw..., cit.

66 DAHLEN, L. y LAGERKVIST, A. "Pay as you throw. Strengths and weaknesses of weightbased billing in household waste collection systems in Sweden", en Waste Management, núm. 30, 2010, pp. 23-31.

$67 \quad$ Es lo que se ha dado en denominar "turismo de residuos", es decir, el hecho de llevar los residuos a zonas donde no se aplica el pago por generación o deshacerse de los residuos ilegalmente.

68 Ibidem.
} 
una política de tratamiento de residuos, coercitiva, aplicable a todos los eslabones de la cadena alimentaria, llevando a cabo el principio de quien contamina paga" 69 .

A pesar de que la norma francesa no establece incentivos negativos o esquemas de PAYT, los esquemas de PAYT que muchos países aplican en el ámbito de los residuos en general, pueden ser aplicados al caso concreto de los residuos orgánicos y, por ende, los residuos alimentarios. En este caso, proponemos que se invoque el principio de quien desperdicia paga (waster pays principle), de modo que se aplique una tasa municipal en función de los residuos que generen a los hogares, además de a distribuidores, sector de la restauración y otros sujetos también sometidos a la tasa de residuos municipales ${ }^{70}$. Como se indicó anteriormente, los residuos alimentarios son grandes generadores de gases de efecto invernadero, especialmente cuando van a parar a los vertederos. De este modo, el principio busca reducir la externalidad negativa en forma de daño ambiental al imputar a hogares y comercios los costes sociales medioambientales generados.

La Ley 7/1985, de 2 de abril, reguladora de las Bases del Régimen Local, establece en su artículo 26.1 unas competencias mínimas obligatorias para todos los municipios dentro de las cuales figura la recogida de residuos. El mismo artículo especifica que los municipios con población superior a los 5.000 habitantes deberán prestar también el servicio de tratamiento de residuos. La tasa es el tipo de ingreso elegido por la mayoría de municipios para financiar el servicio de recogida y tratamiento de residuos urbanos, y forma parte de los recursos de que disponen las entidades locales y, en particular, los municipios. El Real Decreto Legislativo 2/2004, de 5 de marzo, por el que se aprueba el texto refundido de la Ley Reguladora de las Hacienda Locales, en el artículo 2 enumera los recursos de las entidades locales dentro de los cuales figuran los

$69 \quad$ Resolución del Parlamento Europeo, de 19 de enero de 2012, sobre cómo evitar el desperdicio de alimentos: estrategias para mejorar la eficiencia de la cadena alimentaria en la UE $(2011 / 2175$ (INI).

${ }_{70}$ Los distribuidores son personas jurídicas que, al igual que los hogares (personas físicas) resultan beneficiados por el servicio de recogida y tratamiento de residuos. En el caso de la restauración y otros establecimientos nos referimos, además de la restauración, a las actividades de alojamiento, sanitarias, culturales y administrativas, que también generan residuos orgánicos y que son sujetos pasivos de la tasa. Recordemos que todos estos sujetos forman parte de lo que hemos denominado la fase de consumo de la cadena alimentaria. 
tributos propios, categoría en la que se incluyen las tasas ${ }^{71}$. Según el artículo 20 de la misma norma, las entidades locales podrán establecer tasas por la prestación de servicios públicos de competencia local que no sean de solicitud o recepción voluntaria para los administrados. En particular, dicho precepto enumera el servicio de recogida de residuos sólidos urbanos, tratamiento y eliminación de residuos como uno de los servicios que pueden ser financiados a través de tasas.

La aplicación de dicha tasa no solo provee de recursos a los municipios para financiar el servicio público, sino que en este caso también tiene una finalidad extrafiscal. Esto es, más allá de la finalidad recaudatoria puede servir como un instrumento de incentivo económico ${ }^{72}$. Nuestra propuesta es el establecimiento de un sistema PAYT o pago por generación a aplicar a los hogares y demás sujetos pasivos en el contexto de la tasa municipal de residuos urbanos ${ }^{73}$. La aplicación de un sistema PAYT o pago por generación tiene su base en la recogida selectiva de los residuos, y supone que el sujeto pasivo debe separar los residuos orgánicos del resto de residuos, una práctica que, en el caso de Cataluña por ejemplo, se realiza en la mayoría de municipios ${ }^{74}$. Además, el gobierno catalán, en el Decreto PRECAT20, señala como uno de los objetivos de prevención para el año 2020 , la reducción en un $50 \%$ en el peso del

71 Los tributos propios de las entidades locales están formados por las tasas, las contribuciones especiales y los impuestos. Además de los tributos propios, las entidades locales disponen de los recargos exigibles sobre los impuestos de las Comunidades Autónomas o de otras entidades locales. La imposición y supresión de los tributos y recargos se aprueba en las correspondientes ordenanzas fiscales del municipio (artículo 15 del Real Decreto Legislativo 2/2004).

72 El artículo 2 de la Ley 58/2003, de 17 de diciembre General Tributaria establece que los tributos, dentro de los cuales se encuentran las tasas, además de ser medios para obtener recursos para la financiación de los gastos públicos, puedan servir como instrumentos de política económica general.

73 Recordemos que la provisión u oferta del servicio de recogida y tratamiento de residuos corresponde al municipio, con independencia del hecho de que la producción de dicho servicio la realice el sector privado, como ocurre en el caso de muchos municipios. Este hecho es independiente de la exigencia de la tasa por parte del municipio.

$74 \quad$ Según datos de la Agència de Residus de Catalunya (Balanç de les dades estadístiques de residus municipals de l'any 2018. Departament de Territori i Sostenibilitat. Generalitat de Catalunya) el índice de recogida selectiva neta en Cataluña se sitúa en el $33,4 \%$ del total de residuos generados, mientras que la recogida selectiva bruta es del $41,8 \%$, con datos para 2018 . La recogida selectiva neta es la que no tiene en cuenta los denominados "impropios", es decir, aquellos residuos que no corresponden a la fracción objeto de recogida. En el mismo documento se señala que 780 municipios catalanes (el $82,4 \%$ ) realizan la recogida selectiva de la materia orgánica. 
desperdicio de alimentos en los ámbitos de la distribución al por menor, la restauración, catering y el ámbito doméstico, respecto del año base $2010^{75}$

Por lo que se refiere al diseño de la tasa, compartimos la propuesta de PUIG VENTOSA de gravar de forma más que proporcional la generación de residuos y definir una tasa "marginalmente creciente" lo que significa que, a más quilos generados por persona más se paga por quilo. Este autor justifica este diseño de la tasa en el sentido de que "el impacto ambiental de los residuos también es marginalmente creciente"76. Hay que tener en cuenta que el importe de la tasa a pagar por los sujetos pasivos no puede superar el coste del servicio recibido, es decir, la recogida y tratamiento de residuos ${ }^{77}$. Siguiendo el argumento de PUIG VENTOSA, lo que recaudan los municipios a través de la tasa de residuos es sólo una parte del coste del servicio de modo que existe margen para establecer las tasas marginalmente crecientes sin que los ciudadanos paguen por encima del coste del servicio.

En un estudio de IRIANI et al. sobre el estado de las tasas de residuos en España con datos para el año 2015, se señala que una de las opciones más extendidas entre los municipios españoles es la de hacer pagar una tasa de residuos fija ${ }^{78}$. Los autores señalan que "una tasa fija independiente de la cantidad de residuos generada no genera incentivos a reciclar ya que el precio que se paga por unidad de basura adicional es cero".

Así pues y, en el caso de los hogares, distribuidores, sector de la restauración y otros sujetos, abogamos por el establecimiento de un sistema PAYT o de pago por generación en el contexto de la tasa de residuos municipal con un diseño de la tasa marginalmente creciente (en el que el pago es mayor cuanto mayor es el residuo generado). Proponemos que este sistema se aplique a la fracción

\footnotetext{
75 Real decreto 210/2018, de 6 de abril, por el que se aprueba el Programa de prevención y gestión de residuos y recursos de Cataluña (PRECAT20).

${ }_{76}$ PUIG VENTOSA, I. "Definición de tasas municipales de gestión de residuos para incidir en la reducción y el reciclaje", en ROMANO, D. y BARRENECHEA, P. (coords.) Instrumentos económicos para la prevención y el reciclaje de los residuos urbanos, Bakeaz-Fundación Ecología y Desarrollo, 2001.

77 En concreto, el artículo 24.2 del RDLLRHL, establece que "el importe de las tasas por la prestación de un servicio o por la realización de una actividad no podrá exceder en su conjunto, del coste real o previsible del servicio o actividad de que se trate o, en su defecto, del valor de la prestación recibida".

${ }_{78}$ En este caso, todos los hogares pagan la misma cantidad. IRIANI, M. et al, Las tasas de residuos en España 2018, Fundació ENT, 2018.
} 
orgánica, una parte importante de la cual está formada por los residuos alimentarios. En este sentido, la tasa incentiva a prevenir y reducir el desperdicio de alimentos — planificando mejor las compras y los menús, reciclando los productos, conservándolos mejor, etc.- puesto que cuantos menos residuos orgánicos generan los hogares, menos pagarían en concepto de tasa. La reducción de los residuos alimentarios conllevaría, en fin, el consiguiente menor impacto ambiental.

Desde el punto de vista de la justicia o equidad, el diseño de este tipo de tasa resulta a nuestro juicio equitativo puesto que relaciona el pago con los residuos orgánicos que cada hogar genera ${ }^{79}$. Este sistema permite dar cumplimiento al principio de "quien contamina paga" o "quine desperdicia paga" a través de la tasa de residuos. Se genera un incentivo económico consistente en el vínculo entre el pago de la tasa y la cantidad de los residuos orgánicos generados. Se trata de premiar a los hogares y empresas de distribución que se esfuerzan en separar de forma adecuada los residuos y, en particular, reducir los residuos orgánicos y, por ende, el desperdicio alimentario y su consiguiente impacto ambiental.

Entendemos que se trata de una opción teórica cuya implementación práctica requiere, como se ha dicho anteriormente, la recogida selectiva de la fracción orgánica en los municipios y el diseño técnico del modelo que podría basarse en el sistema de pago por volumen (por ejemplo, sobre la base de bolsas estandarizadas) $)^{80}$.

En fin, los municipios deben tener un papel relevante y activo en la lucha contra el desperdicio alimentario tanto desde el punto de vista normativo, a través de las ordenanzas municipales, y con el uso de instrumentos de incentivo económico de PAYT. Al ser la Administración más cercana a los ciudadanos, se les presupone un impacto mayor. Adicionalmente, deberá recurrirse a programas de sensibilización y educativos para informar a la población sobre el desperdicio

\footnotetext{
79 Por el contrario, en un sistema de tasa de residuos fija, los hogares que generan menos residuos orgánicos están financiando a los que generan más, lo que no nos parece equitativo.

80 Un sistema de pago por peso de los residuos sería más exigente a nivel técnico y requeriría más inversiones por parte de los municipios.
} 
y los impactos ambientales de los residuos alimentarios. Estas acciones deben ser complementarias a las medidas normativas y fiscales.

\section{CONCLUSIONES}

El problema del desperdicio de alimentos se produce sobre todo en los últimos eslabones de la cadena alimentaria, en concreto, en la fase de consumo final, en especial, en el caso de los distribuidores y hogares. Desde un punto de vista económico, el desperdicio alimentario puede interpretarse como una externalidad negativa que genera costes sociales o medioambientales. Se trata de una externalidad global y compleja puesto que los costes medioambientales asociados a los residuos alimentarios recaen sobre la sociedad en su conjunto.

En el contexto europeo, Francia ha sido el primer país en legislar mediante una aproximación transversal y multimodal el problema del desperdicio alimentario, estableciendo una pluralidad de medidas dirigidas, especialmente, a los distribuidores, aunque también a los consumidores.

A la luz de la normativa francesa y de la teoría de las externalidades, en este trabajo se articulan distintas propuestas para prevenir y reducir el desperdicio de alimentos. Nuestras propuestas son, en esencia dos: de un lado, la imposición de la obligación de donar alimentos a los distribuidores y la prohibición de tirar los que sean aptos para el consumo humano. Esta es una medida de comando y control. De otro lado, se propone la imposición de una tasa que grave a aquellos que tiren más alimentos. Esta es una medida de incentivo económico.

La prohibición de tirar y la obligación de donar se inspiran en la normativa francesa. En concreto, se propone que la normativa española en materia de residuos —estatal básica, y la autonómica en su desarrollo y ejecución- obligue a los distribuidores a la separación de los excedentes de alimentos todavía aptos para su consumo del resto de los residuos orgánicos de modo que no se tiren y, en su lugar, se donen. Para acompañar y reforzar esta norma imperativa, se propone el uso de sanciones en caso de incumplimiento, así como de beneficios fiscales a modo de desgravación en el impuesto de sociedades.

Como el desperdicio alimentario no se ciñe en exclusiva a las empresas y establecimientos de venta al por menor, se proponen medidas susceptibles de 
causar un impacto real también en los hogares —ámbito que hasta ahora solo se aborda con medidas de sensibilización e información. En este sentido, se propone que en el caso de los hogares —además de distribuidores, sector de la restauración y otros sujetos - se establezca un sistema pay-as-you-throw o pago por generación en el contexto de la tasa de residuos municipal con un diseño de la misma marginalmente creciente, en el que el pago es mayor cuanto mayor es el residuo orgánico generado. Se trata de una manifestación del principio del contaminador pagador.

Con las medidas propuestas, a partir de la teoría de las externalidades y de la legislación francesa, se quiere fijar las bases para una normativa que logre la reducción del desperdicio alimentario limitando el impacto ambiental del mismo.

\section{BIBLIOGRAFIA}

Agència de Residus de Catalunya, Diagnosi del malbaratament alimentari a Catalunya, Generalitat de Catalunya, 2012.

BIO INTELLIGENCE, Preparatory Study on Food Waste Across EU 27, Comisión Europea, 2010.

CASTRO, M., "La Responsabilidad Social de las Empresas, o un nuevo concepto de empresa", en Revista CIRIEC, núm. 53, 2005, pp. 29-51.

ChABOUD, G. y DAVIRON, B., "Food losses and waste: Navigating the inconsistencies", en Global Food Security, vol. 12, 2017, pp. 1-7.

CicAtiello, C. et al., "The value of food waste: An exploratory study on retailing", en Journal of Retailing and Consumer Services, vol. 30, 2016, pp. 96-104.

CoAse, R. H., "The Problem of Social Cost», en The Journal of Law and Economics, vol. III, 1960, pp. 1-44.

Comisión Europea, Market study on date marking and other information provided on food labels and food waste prevention, 2018.

CROPPER, M. L. y OATES, W. E., "Environmental Economics: A survey”, en Journal of Economic Literature, vol. XXX, 1992, pp. 675-740. 
DAHLEN, L. y LAGERKVIST, A., "Pay as you throw. Strengths and weaknesses of weight-based billing in household waste collection systems in Sweden", en Waste Management, núm. 30, 2010, pp. 23-31.

DíAZ-RuIZ, R., CostA-FonT, M., GIL, J. M., "Moving from food-related behaviours: an alternative approach to understand household food waste generation", en Journal of Cleaner Production, núm. 172, 2018, pp. 1140-1151.

DORWARD, L. J., "Where are the best opportunities for reducing greenhouse gas emissions in the food system (including the food chain)? A comment", en Food Policy, vol. 37, 2012, pp. 463-466.

EPA (United States Environmental Protection Agency), Pay-As-You-Throw. Lessons Learned about Unit Pricing, 1994.

EVANS, D., "Beyond the throwaway society: ordinary domestic practice and a sociological approach to household food waste", en Sociology, núm. 46, 2011, pp. 41-56.

FAO, Food wastage footprint, Impacts on Natural resources, Summary report. Roma, 2013.

FAO, Background paper on the economics of food loss and waste. Working paper, Roma, 2014.

FUSIONS, Estimates of European food waste levels, Estocolmo, 2016.

FUSIONS, Market-based instruments and other socio-economic incentives enhancing food waste prevention and reduction, 2016.

Graham-Rowe, E., Jessop, D. C. y Sparks, P., "Identifying motivations and barriers to minimizing household food waste", en Resources, Conservation and Recycling, núm. 84, 2014, pp.15-23.

GuSTAVSSON, J. et al., Las pérdidas y el desperdicio de alimentos a nivel mundial. Extensión, causas y prevención, FAO, Roma, 2011.

IPPC, Intergovernmental Panel on Climate Change. Climate Change and Land. Agosto 2019.

IRIANI, M. et al, Las tasas de residuos en España 2018, Fundació ENT, 2018. 
KolshtAD, C. D., Economía ambiental, Oxford University Press, México, D.F., 2001.

Krugman, P. y Wells R., Microeconomía, Reverté, Barcelona, 2013.

Ministerio de Agricultura, Pesca y Alimentación, Estrategia "Más alimento, menos desperdicio", 2013.

MONDÉJAR-JIMENÉZ, J.A. et al. (2016), "From the table to waste: an exploratory study on behaviour towards food waste of Spanish and Italian youths", en Journal of Cleaner Production, núm. 138, 2016, pp. 8-18.

Montagut, X. y Gascón, J., Alimentos desperdiciados. Un análisis del derroche alimentario desde la soberanía alimentaria, Icaria, Barcelona, 2014.

Parlamento Europeo, Resolución del Parlamento Europeo, de 19 de enero de 2012, sobre cómo evitar el desperdicio de alimentos: estrategias para mejorar la eficiencia de la cadena alimentaria en la UE (2011/2175(INI).

PAscó-FONT, A. y MONTOYA, A., "Incentivos económicos y protección ambiental: una revisión de la experiencia norteamericana y europea", en Notas para el debate, núm. 11, 1993, pp. 43-60.

Pigou, A. C., The Economics of Welfare, Palgrave Macmillan, 2013.

Pinstrup-Andersen, P. et al., Las pérdidas y el desperdicio de alimentos en el contexto de sistemas alimentarios sostenibles. Un informe del Grupo de alto nivel de expertos en seguridad alimentaria y nutrición del Comité de Seguridad Alimentaria Mundial, FAO, Roma, 2014.

PLA, L. et al. "La paradoja alimentaria contemporánea en el marco de la justicia ambiental", en Ludus Vitalis, núm.49, 2018, pp. 133-152.

PRIEFER, C. et al., "Food waste prevention in Europe-A cause-driven approach to identify the most relevant leverage points for action", en Resources, Conservation and Recycling, vol.109, 2016, pp. 155-165.

Puig Ventosa, I., "Definición de tasas municipales de gestión de residuos para incidir en la reducción y el reciclaje", en ROMANO, D. y BARRENECHEA, P. (coords.) 
Instrumentos económicos para la prevención y el reciclaje de los residuos urbanos, Bakeaz-Fundación Ecología y Desarrollo, 2001.

PUIG Ventosa, I., "Incentivos económicos para avanzar hacia la reducción y el reciclaje de residuos urbanos", en Revista interdisciplinar de gestión ambiental, núm. 48, 2002, pp. 22-32.

Puig Ventosa, I., "Charging systems and PAYT experiences for waste management in Spain", en Waste Management, núm. 28, 2008, pp. 2767-2771.

QUINTANILLA, I., Psicología del consumidor, Pearson Educación, Madrid, 2016.

REICHENBACH, J., "Status and prospects of pay-as-you-throw in Europe_A review of pilot research and implementation studies". Waste Management, 28, 2008, p. 2809-2814.

SAlAmero TeIXIDÓ L., "El modelo francés de lucha contra el despilfarro de alimentos", en Dereito: revista xurídica da Universidade de Santiago de Compostela, Vol. 27, núm.1. 2018.

SalAmero TeIXIDÓ L., "El desperdicio de alimentos", en Salamero TeIXIDó L. (dir.) Manual básico de Derecho alimentario, Tirant Lo Blanch, Valencia, 2019.

SalAmero TeIXIDÓ, L., "Nuevo reto medioambiental en la Unión Europea: la prevención y gestión de los residuos alimentarios según la Directiva Marco de Residuos tras su última modificación", en Revista Española de Derecho Administrativo, núm. 203, 2020.

SCHNEIDER, F., "Wasting Food. An Insistent Behaviour", en Waste-The Social Context' 08. Urban Issues and Solutions. Shaw Conference Centre, May 2008, Edmonton, Alberta, Canadá, 2008.

StiglitZ, J. E. y RosengaRd, J. K., La economía del sector público, Antoni Bosch, Barcelona, 2016.

StUART, T., Despilfarro. El escándalo global de la comida, Alianza, Madrid, 2011.

Tribunal de Cuentas Europeo, La lucha contra el despilfarro de alimentos: una oportunidad para la UE de hacer más eficiente el empleo de recursos en la cadena de suministro alimentario, Luxemburgo, 2016. 
UNEP (United Nations Environment Programme, FAO), Prevention and Reduction of Food and Drink Waste in Businesses and Households: Guidance for Governments, Local Authorities, Businesses and Other organizations. Version 1.0, 2014.

WILLIAMS, H., et al. "Reasons for household food waste with special attention to packaging", en Journal of Cleaner Production, núm. 24, 2013, pp. 141-148.

YeRA, T. y PIN J.R., La Demanda Social de la Responsabilidad Pública. Marco de referencia sobre RSC y buen gobierno IESE Business School, Universidad de Navarra, 2010. 